\title{
Characteristic Properties of Advanced Coil-External Electrodes of Fluorescent Lamps
}

\author{
Lyuji Ozawa \\ Independent Scholar, Beijing, China \\ Email: rotsun4@hotmail.com
}

How to cite this paper: Ozawa, L. (2018) Characteristic Properties of Advanced CoilExternal Electrodes of Fluorescent Lamps. Journal of Materials Science and Chemical Engineering, 6, 33-64.

https://doi.org/10.4236/msce.2018.62004

Received: January 18, 2018

Accepted: February 11, 2018

Published: February 14, 2018

Copyright $\odot 2018$ by author and Scientific Research Publishing Inc. This work is licensed under the Creative Commons Attribution International License (CC BY 4.0).

http://creativecommons.org/licenses/by/4.0/

(c) (i) Open Access

\begin{abstract}
The coil-EEFL lamps, which are operated with DC driving circuit, have studied. The figure of the merit of the coil-EEFL lamps is the quantum efficiency $\left(\eta_{q}\right)$ that is given by the emitted visible photons by one moving electron in the FL lamp. The electrons in the FL lamps move on in the superconductive vacuum $(R=0)$ in the positive column at above room temperature, giving rise to the astronomical $\eta_{\mathrm{q}}=10^{13}$ visible photons $\left(\mathrm{m}^{3} \cdot \mathrm{s}\right)^{-1}$. Miraculously, the developed coil-EEFL lamps in the parallel connections light up with $\mathrm{W}_{\mathrm{DC}}=0$, without the sacrifice of the illuminance $\left(\mathrm{lm} \cdot \mathrm{m}^{-2}\right)$. Furthermore, the scraped 40 W-HCFL lamps revitalize to the coil-EEFL lamps, promising the operation life longer than $10^{6}$ hours. The shallow gap between phosphor screen and positive column can be made by side by side arrangement of the low voltage CL phosphor particles and PL phosphor particles. The coil-EEFL lamps in parallel connections may contribute to the Green Energy Projects of UN.
\end{abstract}

\section{Keywords}

Green Energy, FL Lamps, Power Consumption, Operation Life, Superconductive Vacuum

\section{Introduction}

Our life activity extends to the night time in houses, offices in buildings, stores in shopping malls, and outdoor streets which are illuminated by the incandescent lamps that generate the visible lights by the moving electrons in the vacuum between atoms [1] [2] [3]. The word of the candescence comes from the ancient Greek that means the lights from the fire flame by chemical reactions of organic compounds with oxygen in air. After the finding of atoms and electrons, the lights are generated by the moving electrons in metals, solids and gases, which atoms are arranged with the different conditions in the vacuum. The commercial 
lamps at the present time are the incandescent lamps. The incandescent lamps consume the electric power in the operation. The typical incandescent lamps at the present time are a) tungsten (W) filament lamps, b) LED lamps, and c) fluorescent lamps.

The Green Energy Project by UN is a most important subject at present time in order to reduce the polluted air on our planet Earths. According to the report of COP (Conference of particles, 2015) of the UN, the electric power consumption of the incandescent lamps on the world is around $31 \%$ of the totally generated electric powers on the world. For the contribution of the UN projects, we must find out which incandescent lamp has the potential for the contribution to the Green Energy Project (Paris Agreement) by UN. At the present time, there are a few commercial incandescent lamps on the market. We must select a candidate of the incandescent lamp with the science.

The human eyes have adjusted to the daytime scenery under the slightly overcasting sky for more than 5 million years. The daytime scenery is given by the illuminance $\left(300 \mathrm{~lm} \cdot \mathrm{m}^{-2}\right)$, or luminance $\left(300 \mathrm{~cd} \cdot \mathrm{m}^{-2}\right)$, corresponding to the $1 \times$ $10^{25}$ visible photons $\left(\mathrm{m}^{2} \cdot \mathrm{s}\right)^{-1}$. The scientific study on the light sources should be made by a) the numbers of the visible photons $\left(\mathrm{m}^{2} \cdot \mathrm{s}\right)^{-1}$ that can be calculated from the quantum efficiency, $\eta_{q}$, and $\mathrm{b}$ ) the numbers of the moving electrons per second of the incandescent lamps. With this reason, we have figured out the $\eta_{\mathrm{c}}$ and the numbers of the electrons involved in the lighting incandescent lamps. The numbers of the moving electrons in the incandescent lamps are calculated from the electric current based with the flowing electrons in the lighting incandescent lamps. The study on the incandescent lamps had studied for more than 100 years. Their studies have summarized many publications and Handbooks [4]-[9]. Unfortunately we cannot find the $\eta_{\mathrm{q}}$ and the numbers of the flowing electrons in the established candescent lamps in the past publications.

The most popular incandescent lamps on the market at present time are a) W-filament lamp, b) LED lamp, and c) fluorescent (FL) lamp. We cannot find the $\eta_{\mathrm{q}}$ of those incandescent lamps. Next difficulty is the calculation of the moving electrons in the lighted incandescent lamps. It should note that as the lamps are operated with the AC driving circuit, two kinds of the electric currents are involved in the operation; e.g., a) moving electrons and b) induced AC current. We cannot calculate the numbers of the flowing electrons in the lighted incandescent lamps with the induced AC current. We must take the DC electric current for the selection of a best incandescent lamp for the contribution to the Green Energy Project by UN. Anyhow, we will find out the $\eta_{\mathrm{q}}$ of the established incandescent lamps at first.

\section{Quantum Efficiency of Existing Incandescent Lamps on Market}

\subsection{W-Filament Lamps}

The electrons in the metal incandescent lamps, like as $\mathrm{W}$-filament lamp, move 
on in the bonding orbital shell. The moving electrons never step in the vacuum between metal atoms at the lattice sites. The moving electrons in the metal lamps inevitably have the electric resistance $(R)$ that is caused by the thermal perturbation from the thermally vibrating atoms at the lattice sites. The lights of the metal lamps come from the heated metal filament by the Joule Heat that the temperature is given by $\mathrm{I}^{2} R$, where $\mathrm{I}$ is electric current and $R$ is electric resistance. The emitted photons from the heated metal distribute in the wide spectrum wavelengths from the ultra-violet lights to the infra-red lights. We cannot evaluate the $\eta_{\mathrm{q}}$ of the metal lamps. The evaporation of the metal atoms from the heated metal-filament at the high temperatures $\left(>1000^{\circ} \mathrm{C}\right)$ determines the short operation life. The metal incandescent lamps are the electric power hungry lamps.

\subsection{LED Lamps}

The LED lamps are on the lighting market in the last years with the advertisement as the energy saving lights, without the proof with the science. We had the conclusion on 1980 in USA that the LED lamps did not have the advantage as the energy saving light source. Then, the papers on the LED lamps allowed the publication. But no one describes the limitation of the LED lamps in their publications. We do not change the conclusion. After the publications, the study on the LED lamps shifts to Asian countries. They have developed the present LED lamps. The fundamentals of the lighting mechanisms are the same that we have studied in the past.

The LED lamps use the moving electrons in the III-V compounds. The LED lamps never have the moving electrons in the bonding shells of the solids. This is because atoms in III-V compounds are bounded with the covalent bonding that does not have an electron vacancy in the bonding shell. The pure III-V compounds of the LED lamps are electric insulator. As the III-V compound contains a small amount of the impurities (IV-atoms), each impurity atom in the III-V compound has one extra electron in the bonding shell. The extra electrons in the impurity atoms stay in the narrow vacuum space between atoms at the lattice site with the separation distance at around $10^{-10} \mathrm{~m}$. As the III-V compound has metal electrodes at the both ends, the extra electrons in the vacuum between atoms at the lattice sites move on the narrow vacuum space under the electric field between the electrodes. Thus the impure compound changes to the electrically conductive compound. This is n-type III-V semiconductor. As the III-V compounds contain the small amount of the impurity (II-atoms), the bonding shell of the impurity atoms in the III-V compound has one vacancy of the electron in the upper shell in the bounding atoms. The impurity at the localized position may pick up the electron from the vacuum between atoms at lattice sites. The picked electrons by the impurity are unstable in the bounding shell of the impurity, so that the picked electron returns to the vacuum between atoms at the lattice sites. The compounds that have the empty of the bounding electron are called as p-type semiconductor. The n-type and p-type semiconductors are the electric conductor but the moving electrons do not generate the light. 
The LED lamps utilize the luminescence centers in the narrow junction layer between n-type and p-type semiconductors. The recombinations of the electrons and holes at the recombination centers generate the visible photons. The colors of the generated lights change with the kinds of the recombination centers. Thus the LED lamps generate the visible photons from the luminescence centers to the visible spectral wavelengths. The commercial LED lamps emit the blue light that is converted to the lights in the various colors by the phosphor particles. Each moving electron in the LED amps loses the kinetic energy by the Joule Heat before the generation of the light. Consequently, the $\eta_{\mathrm{q}}$ is less than 1.0. As described above, the generation mechanisms of the lights from the LED lamps totally differ from the $\mathrm{W}$-filament lamps. The LED lamps emit the visible photons with $\eta_{\mathrm{q}}$ less than 1.0.

The electrons in the LED lamps move on in the vacuum between atoms at the lattice sites that have the separation distance around $10^{-9} \mathrm{~m} \mathrm{[1]} \mathrm{[2]} \mathrm{[3].} \mathrm{There-}$ fore, we cannot use the band model for the generation of the lights from the LED lamps. The band model is given by the projection of the wave-function of the given atom at $k=0$ to two dimensions plane [4]. Therefore, we cannot bend the band model upside or low side on the two dimensional plane. You cannot use the band model for the generation of the lights. If you use the band model, you will have the fake results.

Since the lights are generated by the recombinations of the electrons and holes at the luminescent centers in the junction, we may calculate the numbers of the emitted visible photons per one input electron to the LED lamps. The determined $\eta_{\mathrm{q}}$ of the LED lamps is less than $1.0\left(\eta_{\mathrm{q}} \approx 0.5\right)[1]$. For the illumination of the $1 \mathrm{~m}^{2}$ room, the LED lamp should emit $10^{25}$ visible photons per second. The required electric current is $3.2 \times 10^{6} \mathrm{~A}\left(=10^{25} \times 2 \times 1.6 \times 10^{-19}\right.$ Coulomb per second). The LED lamps are operated with $2.8 \mathrm{~V}$. We may calculate the required electric power consumption of the LED lamps. The calculated $\mathrm{W}_{\mathrm{LED}}$ is $9 \times 10^{6}$ watt $\left(=3.2 \times 10^{6} \mathrm{~A} \times 2.8 \mathrm{~V}\right) \approx 10,000 \mathrm{~kW}$ [1] [2] [3]. It requires a very large amount of the electric power consumption, even though the developers and producers of the LED lamps claim the power saving light source in public media without scientific evidence. As described above, one may allow us to say that the LED lamps are the power hungry light source with the low $\eta_{\mathrm{q}} \approx 0.5$.

\subsection{FL Lamps}

We have found the astronomical $\eta_{\mathrm{q}}=10^{13}$ visible photons $\left(\mathrm{m}^{3} \cdot \mathrm{s}\right)^{-1}$ of the lighted FL lamps [1] [2] [3]. The astronomical $\eta_{\mathrm{q}}=10^{13}$ visible photons $\left(\mathrm{m}^{3} \cdot \mathrm{s}\right)^{-1}$ are caused with the superconductive vacuum at above room temperature. The moving electrons in the superconductive vacuum in the Ar gas space do not have the electric resistance, $R$. The moving electrons do not receive the thermal perturbation from the thermal vibration of Ar atoms at floating position in vacuum. Furthermore, the numbers of the moving electrons in the positive column is $2 \times$ $10^{15}$ electrons $\left(\mathrm{m}^{3} \cdot \mathrm{s}\right)^{-1}$. The numbers of the generated light (photons) from the FL lamps is calculated as $2 \times 10^{28}$ photons $\left(\mathrm{m}^{3} \cdot \mathrm{s}\right)^{-1}\left\{=10^{13}\right.$ photons $\left(\mathrm{m}^{3} \cdot \mathrm{s}\right)^{-1} \times 2 \times$ 
$10^{15}$ electrons\}.

The developments of the FL lamps have long history for 90 years since the inventions [5] [6]. At the present time, the developers of the FL lamps had believed the mature technologies of the commercial FL lamps [7]-[12]. We cannot find the $\eta_{\mathrm{q}}$ of the established FL lamps in the publications. The mature technologies of the FL lamps have made with the similarities with the solid lighting lamps. However, the electrons in the FL lamps move on in the quite different vacuum conditions from the solids [1] [2] [3]. The lighting mechanisms of the solids cannot apply to the FL lamps. We have found that the technologies of the commercial FL lumps have made with the fundamental errors in the operation mechanisms, even though there are many complicated lighting mechanisms in the references [7]-[12]. The vacuum conditions between Ar atoms in the FL lamps are the fundamentals for the study on the FL lamps. We cannot find the vacuum conditions of the lighted FL lamps in the publications. With this reason, we will clarify, at first, the vacuum conditions between Ar atoms in the FL lamps, before the evaluation of $\eta_{\mathrm{q}}$.

Individual Ar atoms in the FL Lamps float in the vacuum with Maxwell-Boltzmann distribution. The separation distance between Ar atoms in the FL lamps is around $1 \times 10^{-6} \mathrm{~m}$ under the Ar gas pressure at $931 \mathrm{~Pa}$ (= 7 Torr). Individual Ar atoms in the FL lamp isolate each other. This means no overlap of the wave function of the Ar atoms floated in the vacuum. The isolation of the wave function of the Ar atoms in the FL lamps can be detected by the measurement of the absorption spectrum with a spectrometer. The measured spectrum consists with the sharp lines, indicating that each Ar atom isolates in the vacuum of the FL lamps. The numbers of the detected absorption lines are higher than the numbers of the intrinsic energy levels. The extra absorption lines attribute to the split-lines of the intrinsic energy level by the Stark Effect. The Stark Effect indicates that the vacuum of the unlighted FL lamps fills up with the negative electric field from the electrons in the uppermost electron shell of the Ar atoms. The vacuum between Ar atoms in the unlighted FL lampas fills up with the negative electric field. The negative electric field in the vacuum between Ar atoms rejects the injected electrons from the metal electrode to the Ar gas space. The electron from the metal electrodes, including the thermoelectrons from the heated $\mathrm{BaO}$ particles, at the both sides of the FL lamps never steps in the vacuum between Ar atoms. In the past, the studies on the FL lamps faced the difficulty of the break of the electrically insulating vacuum between Ar atoms which float in the vacuum [7]-[12]. At first, we must find out a way to break out the electrically insulated vacuum in the unlighted FL lamps. Then we know the vacuum in the lighted FL lamps changes to the electrically conductive vacuum.

Recently we have found a solution that is the formation of the volume of glow light on the sharp needle electrodes [1] [2] [3]. The conditions of the insulating vacuum between Ar atoms surely change to the electric conductive vacuum in the volumes of the glow (or corona) lights. So far as the volumes of the glow light are formed on the needle electrodes at both ends of the FL lamp [1] [2] [3] 
[13], the volume of the glow light contains $\mathrm{Ar}^{1+}$, free electron, excited $\mathrm{Ar}$ atoms $\left(\mathrm{Ar}^{*}\right)$ and $\mathrm{Ar}$ atoms. Only $\mathrm{Ar}^{*}$ emits the sky-blue light. $\mathrm{Ar}^{1+}$, free electrons and $\mathrm{Ar}$ atoms are invisible particles in the volume of the glow light by the naked eyes. We may use the glow light as the monitor of the formation of the volume of the glow light. The invisible $\mathrm{Ar}^{1+}$ and free electrons are the majority in the volume of the glow light. The thickness of the glow light on the needle metal electrodes is 3 $\times 10^{-3} \mathrm{~m}$. The thickness of the glow light does not change with the applied voltages to the needle electrodes. The numbers of the $\mathrm{Ar}^{1+}$ and electrons are more than 60 times of the $\operatorname{Ar}^{*}$ [1] [2] [3] [13]. The negative electric field in the volume of the glow light is neutralized with the presence of the positive $\mathrm{Ar}^{1+}$. Consequently, the vacuum between Ar atoms in the volume of the glow light electrically changes to the neutral vacuum. Under the electric field between the cathode and anode, $\mathrm{F}_{\mathrm{DC}}$, the electrons move on in the neutralized vacuum in the inside of the volume of the glow light. Weight of the $\mathrm{Ar}^{1+}, \mathrm{Ar}^{\star}$, and $\mathrm{Ar}$ atoms are $1.6 \times 10^{-27} \mathrm{~kg}$. The weight of electron is $9.1 \times 10^{-31} \mathrm{~kg}$. As far as the volume of the glow (or corona) lights is under the $\mathrm{F}_{\mathrm{DC}}$, the free electrons and $\mathrm{Ar}^{1+}$ may move on inside of the volume of the glow lights. The moving speed of the electrons in the glow light is $10^{4}$ times faster as compared with the speed of $\mathrm{Ar}^{1+}$. Consequently, the majority of the moving particles in the volume of the glow light are the electrons.

Under the $\mathrm{F}_{\mathrm{DC}}$, the moving electrons may step out from the volume of the glow light to the nearby Ar gas space. The stepped out electrons may ionize the $\mathrm{Ar}$ atoms at the nearby Ar gas space. Consequently, the $\mathrm{Ar}^{1+}$ in the nearby volume of the glow light neutralizes the negative electric field. The negative electric field between Ar atoms in the FL lamp neutralizes with the moving speed of the electrons at $10^{8} \mathrm{~m}$ per second after the formation of the volume of the glow light. This is the starting condition of the lighting of the FL lamps. The neutral vacuum condition in the lighted FL lamps instantly disappears from the unlighted FL lamp by the recombinations of the $\mathrm{Ar}^{1+}$ and electrons, returning to $\mathrm{Ar}$ atoms. The formation of the neutral vacuum and disappearance of the neutral vacuum are determined by the formation of the volume of the glow lights on the needle electrodes [1] [2] [3].

We have found the simplified lighting mechanism of the FL lamps. In the past 90 years, the scientists and engineers had struggled for the analysis of the lighting mechanisms in the FL lamps with the complications of the lighting mechanisms [7]-[12]. They could not simplify the lighting mechanisms. In this report, we have the new and simplified model for the moving electrons in the vacuum between Ar atoms in the lighted FL lamps. This is a big breakthrough in the study on the FL lamps.

Because the moving electrons in the neutralized vacuum between $\mathrm{Ar}$ atoms do not receive the thermal perturbation from the vibrating neighbor Ar atoms, the moving electrons do not have the electric resistance $(R)$. This means that the vacuum between Ar atoms in the lighted FL lamps provides us the superconductive vacuum at the operation temperatures $\left(>30^{\circ} \mathrm{C}\right)$ of the FL lamps [1] [2] [3]. 
The superconductive vacuum at the temperatures higher than the room temperature $\left(22^{\circ} \mathrm{C}\right)$ is a great advantage to the operation of the lighted FL lamps. The lights from the FL lamps are generated with the moving electrons in the superconductive vacuum. The superconductive vacuum of the lighted FL lamps provide us a great advantage in the study of the FL lamps over the LED lamps. The great advantage of the FL lamps is the astronomical $\eta_{\mathrm{q}}$ of the moving electrons in the FL lamps. The required numbers of the moving electrons for the generation of the $10^{25}$ visible photons $\left(\mathrm{m}^{2} \cdot \mathrm{s}\right)^{-1}$ from the FL lamps is calculated with the DC current at $4 \times 10^{-4} \mathrm{~A}$. $1 \mathrm{~A}$ is given by 1 Coulomb par sec. The electric charge of one electron is $1.6 \times 10^{-19}$ Coulomb. The numbers of electrons in $4 \times 10^{-4} \mathrm{~A}$ are calculated as $2 \times 10^{15}$ electrons $\left[=4 \times 10^{-4} \times\left(1.6 \times 10^{-19}\right)^{-1}\right]$. The details of the calculation are below:

Now we have the electrons which move on in the superconductive vacuum in the lighted FL lamps. As the moving electrons meet the floating Ar atoms, the moving electrons receive the Coulomb's repulsion from the electrons in the electric shells of floating Ar atoms. The moving electrons give some amount of the kinetic energy to the Ar atoms by each Coulomb's repulsion. The floating Ar atoms ionize and/or excite $\mathrm{Ar}$ atoms, generating $\mathrm{Ar}^{1+}$ or $\mathrm{Ar}^{*}$ by each Coulomb's repulsion. We may calculate the numbers of the lighted $\mathrm{Ar}^{\star}$ by one moving electron that is $\eta_{\mathrm{q}}=10^{16}$ photons $\left(\mathrm{m}^{3} \cdot \mathrm{s}\right)^{-1}$ [1] [2] [3]. The origin of the light source in the FL lamps is $\mathrm{Hg}^{\star}$. The concentration of the $\mathrm{Hg}$ atoms in the Ar gas in the FL lamps is $1 \times 10^{-3}$ times of the Ar atoms. Then we have $\eta_{\mathrm{q}}=10^{13}$ invisible UV lights $\left(\mathrm{m}^{3} \cdot \mathrm{s}\right)^{-1}$. The phosphor screen transduces the invisible UV lights to the visible lights with $\eta_{\mathrm{q}} \approx 1.0$. Consequently, we have $\eta_{\mathrm{q}}=10^{13}$ visible photons $\left(\mathrm{m}^{3} \cdot \mathrm{s}\right)^{-1}$ per one moving electron in the lighted FL lamps. The amount of the moving electrons in the lighted FL lamps is empirically determined as $4 \times 10^{-4} \mathrm{~A}$ [1] [2] [3]. The numbers of the moving electrons in the lighted FL lamps are $2 \times$ $10^{15}$ electrons per second. Then we may calculate the numbers of the visible photons from the phosphor screen of the commercial $40 \mathrm{~W}$-HCFL lamps in the outer diameter of $3.2 \times 10^{-2} \mathrm{~m}(\mathrm{~T}-10)$. The calculated numbers of the 40 $\mathrm{W}$-HCFL lamps are $1 \times 10^{25}$ visible photons per second that give the illuminance of $300\left(\mathrm{~lm} \cdot \mathrm{m}^{-2}\right)$. One commercial $40 \mathrm{~W}$-HCFL lamp may have a potential that illuminates the furniture in $1 \mathrm{~m}^{2}$ room with the daytime scenery under the slightly overcastting sky. We will find the electric power consumption $\mathrm{W}_{\text {act }}$ can be reduce to $\mathrm{W}_{\mathrm{DC}}=0$ with the coil-EEFL lamps. The coil-EEFL lamps can be operated with the both $\mathrm{AC}$ and DC driving circuits. The EE electrodes of the coil-EEFL lamps never pickup the AC induced current from the large capacitor $\mathrm{C}_{\mathrm{Ar}}$. But the coil-EEFL lamp picks up the induced AC current from the synchronous polarization of the phosphor particles that is the capacitor $\mathrm{C}_{\text {phos }}$, under the $\mathrm{EE}$. The $\mathrm{C}_{\text {phos }}$ gives rise to the $\mathrm{W}_{\text {act }}$ more than 10 watt, depending on the diameters of the coil-EEFL lamp. On the other hand, under the DC driving circuit, the coil-EEFL lamps never pick up the induced AC current based on the $\mathrm{C}_{\mathrm{Ar}}$ and $\mathrm{C}_{\text {phos }}$, resulting in $\mathrm{W}_{\mathrm{DC}}=0$. The coil-EEFL lamps hold a great advantage as the light source with the $\eta_{\mathrm{q}}=10^{13}$ visible photons $\left(\mathrm{m}^{3} \cdot \mathrm{s}\right)^{-1}$ and $\mathrm{W}_{\mathrm{DC}}=0$ over the 
HCFL and CCFL lamps.

As the conclusion of the quantum efficiency $\eta_{\mathrm{q}}$ of the existing incandescent lamps, we take the coil-EEFL lamps as the unrivaled incandescent light source. The established lighting mechanisms of the HCFL lamps in the past for 90 years are based on the hypotheses. We have quantitatively described the new lighting mechanisms of the FL lamp. Only coil-EEFL lamps have the zero electric power consumption, $\mathrm{W}_{\mathrm{DC}}=0$, with the higher illuminance $\left(\mathrm{lm} \cdot \mathrm{m}^{-2}\right)$ and a long operation life. We may discuss the contribution of the FL lamps to the Green Energy Project by the UN. By the report of COP (Conference of particles, 2015) of the $\mathrm{UN}$, the electric power consumption of the incandescent lamps on the world is around $31 \%$ of the totally generated electric powers on the world. If one considers the electric power consumption by the distribution network on the grand, the operation of the commercial incandescent lamps consume the electric power more than $40 \%$ of the totally generated electric power on the world. Here we must consider a fact that the lightings by the incandescent lamps extend to the developing countries on the world. Accordingly, the air pollution on the Earth gradually increases with $3 \%$ each year. In this report, we will challenge the optimization of the invented coil-EEFL lamps for the contribution to the Green Energy Project on the world.

\section{Revise of LIghting Mechanisms of Established FL Lamps for 90 Years}

Before the description of the coil-EEFL lamps, we must have a good understanding of the studies of the established HCFL lamps for 90 years [5]-[12]. We have found that the fundamentals of the lighting mechanisms of the established HCFL lamps are based on the hypotheses without the scientific proofs. The fundamental error is the determination of the electric power consumption of the lighted HCFL lamps.

\subsection{Incorrect Evaluation of $\mathrm{W}_{\text {act }}$ of HCFL Lamps}

The power consumption of the HCFL lamps is an important subject in the study on the HCFL lamps. The commercial HCFL lamps can be operated with the DC driving circuit. The power consumption $\left(\mathrm{W}_{\mathrm{DC}}\right)$ of the external driving circuit of the lighted HCFL lamps is surely zero, $\mathrm{W}_{\mathrm{DC}}=0$, but the operation life is the extremely short, less than 100 hours. For the practical use of the FL lamp, the long operation life is essential requirement. The $40 \mathrm{~W}$-HCFL lamps are operated with the AC driving circuit with $50 \mathrm{~Hz}$. Recently the HCFL lamps are operated with the frequencies higher than $30 \mathrm{kHz}$. Here arises a fundamental error for the determination of the AC electric power consumption.

The electric power consumption of the AC driving circuit should be given by the active electric power $\left(\mathrm{W}_{\text {act }}\right)$ of the $\mathrm{AC}$ driving circuit. We have found the erroneous determination of the $\mathrm{W}_{\text {act }}$ with the commercial $40 \mathrm{~W}$-HCFL lamps [9] [10] [11]. The nominal $\mathrm{W}_{\text {act }}$ of the commercial $40 \mathrm{~W}$-HCFL lamps is 40 watt that determines at the electrodes of the HCFL lamps. This is a wrong assignment of 
the $\mathrm{W}_{\text {act }}$. The actual $\mathrm{W}_{\text {act }}$ of the commercial $40 \mathrm{~W}$-HCFL lamps should be determined at the input terminals of the AC driving circuit. It is more than 80 watt, depending on the producers of the HCFL lamps.

The next error is the assignment of the generation energy of the lights of the HCFL lamps. They have analyzed the $\mathrm{W}_{\text {act }}=40$ watt as the generation energy of the light from the HCFL lamps. The determined $\mathrm{W}_{\text {act }}=40$ watt at the electrodes of the HCFL lamps never relates to the generation energy of the lights from the HCFL lamps.

In reality, the heated $\mathrm{BaO}$ particles on the $\mathrm{W}$-filament coils in the HCFL lamps never emit the electrons in to the Ar gas space of the HCFL lamps. With the wrong assignment of the $\mathrm{W}_{\text {act }}=40$ watt for the generation energy of the lights from the HCFL lamps, they never find out the formation of the capacitor $\mathrm{C}_{\mathrm{Ar}}$ in the lighted FL lamps. The erroneous determination of the power consumption of the FL lamps comes from the misunderstanding of the thermoelectron emission from the heated $\mathrm{BaO}$ particles to the Ar gas space of the HCFL lamps.

\subsection{Heated BaO Particles Never Emit Thermoelectrons into Ar Gas Space in FL Lamp}

The established concepts of the HCFL lamps are based on the solid lamps that are operated with the injection of the electrons from the metal electrode (anode) and collection of the arrived electrons by the metal electrode (cathode). The developers of the HCFL lamps believed followings. As the $\mathrm{BaO}$ particles on the $\mathrm{W}$-filament coils heat up to the temperatures above $700^{\circ} \mathrm{C}$, the heated $\mathrm{BaO}$ particles on the cathode directly emit the thermoelectrons into the Ar gas space in the HCFL lamps. The heated $\mathrm{BaO}$ particles on the anode correct the arrived electrons from the Ar gas space. They never studied the details of the thermoelectron emission from the heated $\mathrm{BaO}$ particles in the HCFL lamps. They just believe the contents in the text books [9] [10] [11]. This is the typical case of the learning of the established technologies. Their brain acts as the computers. The human culture has developed by thinking, not the memory of the established concepts. The development of the HCFL lamps is the good example as the computer brain.

The drilled study on the thermoelectron emission from the heated $\mathrm{BaO}$ particles had made with the cathode-ray tubes (CRT) and vacuum radio tubes. The summary of the drilled study are below. The heated Ba atoms at the surface layer on the $\mathrm{BaO}$ particles on cathode metal stably emit the thermoelectrons in to the vacuum at the pressures below $10^{-5} \mathrm{~Pa}\left(10^{-7}\right.$ Torr $)$. The capability of the thermoelectron emission from the heated $\mathrm{BaO}$ particle instantly damages in the vacuum pressures above $0.1 \mathrm{~Pa}\left(>10^{-3}\right.$ Torr $)$. The HCFL lamps contain Ar gas pressure at $930 \mathrm{~Pa}$ (7 Torr). Furthermore, the commercial HCFL lamps are heavily contaminated with the residual gases at the pressure around $1 \mathrm{~Pa}\left(10^{-2}\right.$ Torr). The heated $\mathrm{BaO}$ on the $\mathrm{W}$-filament coils in the HCFL lamps never emit the thermoelectrons and never correct the electrons from the Ar gas space. The 
concept of the thermoelectron emission from the heated $\mathrm{BaO}$ particles can not apply to the cathode and anode of the HCFL lamps. The reality of the function of the $\mathrm{BaO}$ particles on the $\mathrm{W}$-filament coils is below:

The HCFL lamps use the heated bear spot at the end of the $\mathrm{W}$-filament coil for the heating of the volume of the Ar gas space to around $50^{\circ} \mathrm{C}$ in the operation [13]. The real cathode and anode of the HCFL lamps are formed in the Ar gas space with the volume of the corona light that is the $4 \mathrm{G}$ electron source in the HCFL lamps [14]. If the HCFL lamp lights up under the DC operation, the operation life is shorter than 100 hours with the continuous evaporation of the $\mathrm{W}$-filament to the vacuum. For the extension of the operation life, the HCFL lamps are operated with the AC driving circuit at $50 \mathrm{~Hz}$. Under the AC operation, the bear spot of the $\mathrm{W}$-filament coil heats up for the half cycle as the $\mathrm{W}$-filament coil has the positive potential. The bear spot of the $\mathrm{W}$-filament coil does not heat up for subsequent half cycle as the $\mathrm{W}$-filament coil has the negative potential. For holding of the heated temperature of the bear metal spot for the unheated half cycle, the heated bear spot has some amount of the $\mathrm{BaO}$ particles. Because the $\mathrm{BaO}$ particles have the large heat capacitance, the heated bear spot holds the temperature for unheated half cycle. This is the reason that the HCFL lamps use the $\mathrm{W}$-filament coil with the $\mathrm{BaO}$ particles. It is not the thermoelectron emission.

The heated volume of the Ar gas changes to the volume of the corona light under the electric field from the $\mathrm{W}$-filament coils. The corona lights at the both sides of the HCFL lamps act as the cathode and anode of the internal DC electric circuit in the HCFL lamps. The details of the $4 \mathrm{G}$ electron sours in the HCFL lamps refer to the reference [14].

\subsection{Coexistence of Disparity of the External and Internal Electric Circuits in Lighted HCFL Lamps}

The confusion in the study on the HCFL lamps comes from the overlook of the coexistence of external and internal electric circuit in the lighted FL lamps. The coexistence is the essential necessity for the operation of the HCFL lamps [1] [2] [3] [15].

Figure 1 schematically illustrates the coexistence of the external electric circuit and internal electric circuits. Both electric circuits are conjugated with the electric field, without the electron flow between them. The electrodes of the external electric circuit never inject the electrons into the Ar gas space. The external electric circuit of the HCFL lamps is only active with the induced AC current. The induced $\mathrm{AC}$ current is only generated by the capacitor $\mathrm{C}_{\mathrm{Ar}}$ in which forms in the positive column. The formation of the $\mathrm{C}_{\mathrm{Ar}}$ is a new concept in the study on the FL lamps. If the external electric circuit is operated with the DC electric circuit, the electrodes hold the DC voltage, but the external electric circuit does not have the induced electric current. As illustrate in Figure 1, the moving electrons in the internal DC electric circuit only involve in the generation of the lights from the HCFL lamps. The electric field from the electrodes of 


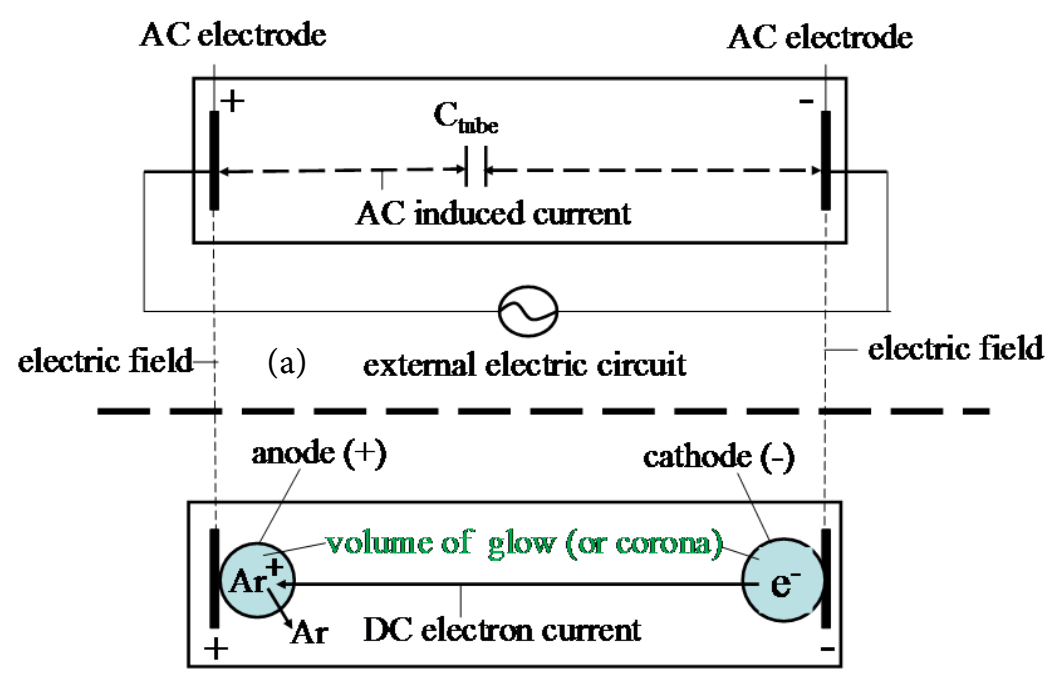

(b) internal electric circuit

Figure 1. Schematic illustration of disparity of external AC driving circuit (a) and internal electric circuit (b) in lighted FL lamp. The both circuits are conjugated with electric field without electron flow.

the external electric circuit helps the formation of the internal DC electric circuit in the Ar gas space.

\subsection{Existence of Capacitor $\mathrm{C}_{\mathrm{Ar}}$ in Lighted Ar Gas Space of FL Lamps}

The capacitor $\mathrm{C}_{\mathrm{Ar}}$ is a new concept in the study of the FL lamps for 90 years. We will describe the details of the formation mechanisms of the $\mathrm{C}_{\mathrm{Ar}}$. The vacuum between floating Ar atoms in unlighted FL lamp is electric insulator. There is no moving electron in the unlighted FL lamps even though the AC voltage applies to the electrodes below the threshold voltage for lighting of the FL lamps. The $\mathrm{C}_{\mathrm{Ar}}$ never forms in unlighted FL lamps. The $\mathrm{C}_{\mathrm{Ar}}$ only exists in the lighted FL lamps. With other words, the $\mathrm{C}_{\mathrm{Ar}}$ forms after ionization of $\mathrm{Ar}$ atoms in the lighted FL lamp. The positive column in the FL lamps always contains the large numbers of $\mathrm{Ar}^{1+}$. Each $\mathrm{Ar}^{1+}$ has one vacancy in the uppermost orbital shell. Therefore, the electron in the uppermost orbital shell in $\mathrm{Ar}^{1+}$ has the displacement space for one electron in the $\mathrm{Ar}^{1+}$. The electron in the $\mathrm{Ar}^{1+}$ may synchronously displace in the uppermost electron shell under the AC electric field between the metal electrodes at the both ends of the lighted FL lamp. The synchronous movement of one electron in the inside of the $\mathrm{Ar}^{1+}$ forms one element of the $\mathrm{C}_{\mathrm{Ar}}$. The capacitance of the $\mathrm{C}_{\mathrm{Ar}}$ is determined by the total numbers of the $\operatorname{Ar}^{1+}\left(\Sigma \mathrm{Ar}^{1+}\right)$ in the lighted FL lamps. The capacitance of the $\mathrm{C}_{\mathrm{Ar}}$ is linearly changed with the Ar gas pressures; the large capacitance with the high Ar gas pressure.

The external AC electric circuit of the FL lamps is only active with the induced AC electric current from the $\mathrm{C}_{\mathrm{Ar}}$, as illustrated (a) in Figure 1. The electrodes at the both side of the FL lamps are never activated with the injection of electrons 
from the electrodes. This is the revised mechanisms of the activation of the electrodes of the lighted FL lamps by the induced AC current. As the FL lamps are operated with the $\mathrm{AC}$ driving circuit, the external driving circuit is only active with the induced $\mathrm{AC}$ current from the capacitor $\mathrm{C}_{\mathrm{Ar}}$ [1] [2] [3]. Figure 2 is the schematic explanation of the formation of $\mathrm{C}_{\mathrm{Ar}}\left(=\mathrm{f} \Sigma \mathrm{Ar}^{1+}\right)$ in the lighted FL lamp. The capacitance of the $\mathrm{C}_{\mathrm{Ar}}$ is linearly changed with the Ar gas pressures in the FL lamps; the large capacitance with the high Ar gas pressures. The gas pressures relate with the operation life of the HCFL lamp, short operation life with the low Ar gas pressures. And the long operation life with the high Ar gas pressures. This is an important conclusion for the development of the reliable HCFL lamps.

\subsection{Formation of Cathode and Anode of Internal Electric Circuit}

Now we describe the internal DC electric circuit in Figure 1(b). The electron source (cathode) and correction of the electron (anode) of the internal DC electric circuit are formed with the formation of the volumes of the glow (or corona) lights which are formed by the electric field from the sharp points of the uncovered needle metal electrodes [1] [2] [3]. The volume of the glow light is also formed with the many sharp points of the polarized polycrystalline phosphor particles $(1,2,3,13,15)$. The HCFL lamps actually use the volume of the heated corona light as the cathode and anode of the internal DC electric circuit. The volume of the corona light is formed with the heated Ar gas space $\left(\sim 50^{\circ} \mathrm{C}\right)$ by the heat from the heated bear spot of the $\mathrm{W}$-filament coils. The volume of the corona light is very large (e.g. equal with the internal diameter of the HCFL lamps), as compared with the volume of the glow light in the $3 \times 10^{-3} \mathrm{~m}$ thickness. The quality of the volume of the corona light is the same with the quality of the glow light, except for the sizes.

In the past study for 90 years, it has belied that the lights from the HCFL lamps are generated by the power consumption of the external AC driving circuit. This is the fundamental mistake in the study on the HCFL lamps, as already mentioned. It is now clear from Figure 1 that the electric power consumption of the external electric circuit of the HCFL lamps does not involve in the generation energy of the lights of the HCFL lamps. The established concept of the direct injection of the electrons into the Ar gas space in unlighted FL lamp is an illusion. The scientific study never accepts the illusion.

The generation of the lights in the HCFL lamps is only made by the electrons that flow between cathode and anode of the internal DC electric circuit. The cathode and anode of the internal DC driving circuit are formed by the volumes of the glow (or corona) lights in the Ar gas space. As the moving electron from the cathode reaches to the anode, the electrons recombines with $\mathrm{Ar}^{1+}$ for returning to Ar atoms, as illustrated in Figure 1(b). There is no consumption of the $\mathrm{Ar}$ atoms in the operation of the FL lamps, promising the infinitive operation life of the lighted FL lamps.

It should note that the operation life of the established HCFL lamps is determined with the loose of the heat source by the cut-off at the heated bear metal 
spot in the W-filament coils. The operation life of the HCFL lamps prolongs with the operation of the external driving circuit with the high frequencies at 50 $\mathrm{kHz}$. The prolonged operation life is about $10^{4}$ hours. We must find the operation life of the lighted HCFL lamp longer than $10^{4}$ hours.

Then, we have found the coil-EEFL lamps [1] [2] [3]. The cathode and anode are formed with the volume of the glow light on the polarized phosphor particles on the inner glass wall by the electric fields from the external electrodes (EEs) on the outer glass wall of the FL lamps. With the internal DC electric circuit, the electrons move from the volume of the glow light as the cathode to the volume of the glow light as the anode. The arrived electron to the volume of the anode recombines with the $\mathrm{Ar}^{1+}$ and returns to Ar atom. There is no consumption of the Ar atoms in the operation of the internal DC electric circuit, promising the long operation life of the coil-EEFL lamp. The coil-EEFL lamps possibly have the operation life longer than $10^{6}$ hours with the reason of no consumption of the $\mathrm{Ar}$ atoms in the operation. If it is so, one may have one coil-EEFL lamp for all his life.

\subsection{Electric Charges on Phosphor Particles in Screens Determine Depths of Gap in Lighted FL Lamps}

With the study on the HCFL lamps, there is no report on the gap between positive column and phosphor screen. They have believed the electrons move on the entire inner volume of the HCFL lamp, including the phosphor screen. They have believed that the electric conductance of the phosphor screen help the moving electrons in the lighted HCFL lamps.

The performance of the lighted FL lamps is seriously influenced with the depths of the gap [16] [17]. In reality, the surface of the phosphor particles in the screens heavily and deliberately contaminated with the microclusters, like as $\mathrm{SiO}_{2}$ gel particles, by the surface treatments. The microclusters on the phosphor particles negatively charge up under the electric field between the cathode and anode, $\mathrm{F}_{\mathrm{DC}}$. The phosphor particles in the screen generate the vertical electric field, $\mathrm{F}_{\text {phos }}$ against $\mathrm{F}_{\mathrm{DC}}$. The approaching electrons to the phosphor particles receive the strong Coulomb's repulsion from the $\mathrm{F}_{\text {phos }}$. The repulsed electrons move on in the positive column where $F_{D C} \geq F_{\text {phos }}$. Naturally, there is the gap in which the moving electrons cannot step in the Ar gas space in which $F_{D C} \leq F_{\text {phos }}$, as illustrated in Figure 2.

If you remove the phosphor screen from the HCFL lamps, you may observe the gap between positive column and inner glass wall. The depth of the gap of the commercial $40 \mathrm{~W}$-HCFL lamps is deeper than $3 \times 10^{-3} \mathrm{~m}$, depending on (a) the thickness of the phosphor screen and (b) quality of the phosphor particles. The depths of the gap control the volume of the positive column in which the electrons move on in the Ar gas space. The depth of the gap seriously influences to the performance of the lighted FL lamps. However, the formation mechanisms of the depth of the gap never study in the past [7] [8] [9] [10] [11]. The depth of the gap determines 1) the volume of the positive column. Accordingly 


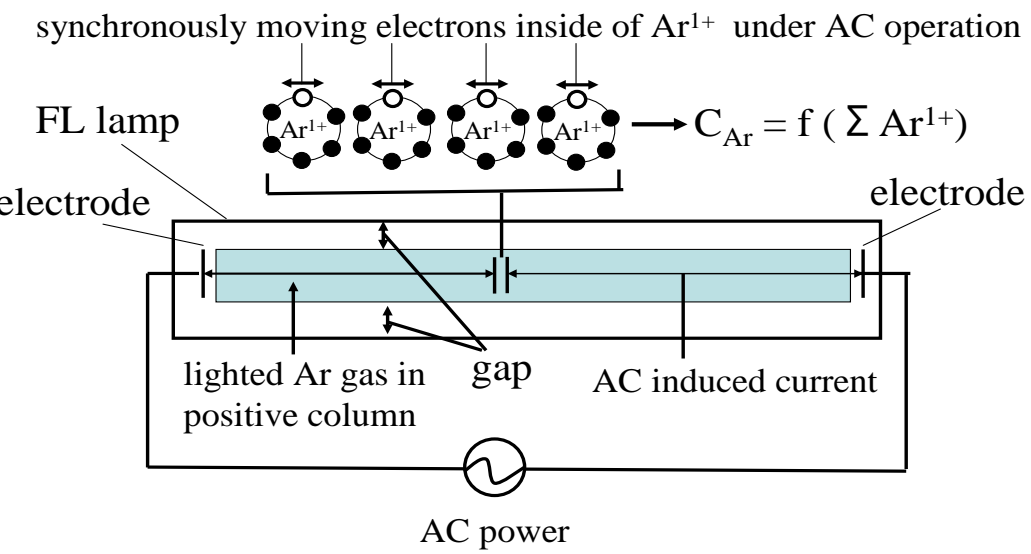

Figure 2. Schematic explanation of formation of $\mathrm{C}_{\mathrm{Ar}}$ in lighted FL lamp.

the depth of the gap determines 2) the inner diameters of the glass tubes of the lighting FL lamps, 3) the evaporation of the $\mathrm{Hg}$ atoms from the $\mathrm{Hg}$ droplets on the phosphor screen, and 4) the optimal luminance $\left(\mathrm{lm} \cdot \mathrm{m}^{-2}\right)$ of the given FL lamps.

For example, total depth of the gap of many commercial HCFL lamps is $6 \times$ $10^{-3} \mathrm{~m}\left(=2 \times 3 \times 10^{-3} \mathrm{~m}\right)$. The total thickness of the glass tube is $2 \times 10^{-3} \mathrm{~m}(2 \times$ $\left.1 \times 10^{-3} \mathrm{~m}\right)$. As for as the HCFL lamps are produced with the established production facilities and operation conditions of the production facilities, the HCFL lamps in the outer diameters narrower than $8 \times 10^{-3} \mathrm{~m}\left\{=(6+2) \times 10^{-3} \mathrm{~m}\right\}$ does not emit the lights. This is the reason that many commercial $40 \mathrm{~W}$-HCFL lamps are produced with the outer glass tubes wider than $3.2 \times 10^{-2} \mathrm{~m}$ (T-10), giving rise to the diameter of the positive column in $2 \times 10^{-2} \mathrm{~m}$. If you reduce the depth of the gap to $3 \times 10^{-4} \mathrm{~m}$, you may produce the HCFL lamps with the glass tubes in the inner diameter of $2 \times 10^{-2} \mathrm{~m}$. The produced HCFL lamps may light up with $50 \%$ higher illuminance $\left(\mathrm{lm} \cdot \mathrm{m}^{-2}\right)$ of the commercial $40 \mathrm{~W}$-HCFL lamps, for instance of the illuminance $\left(500 \mathrm{~lm} \cdot \mathrm{m}^{-2}\right)$. However, the formation of the gap in the lighted $40 \mathrm{~W}$-HCFL lamps has never studied in the past 90 years. The reasons are very simple because they are never studied the electric charges on the phosphor particles in the screen of the lighted HCFL lamps.

We have extensively studied the electric charges of the phosphor screen in the high resolution CRT by the measurement of the voltage dependence curves of the CL of the phosphor screens [16] [17]. The electrons reach on the phosphor particles as if the phosphor particles have the clean surface chemically and physically. Then we have extensively studied the phosphor screens in the HCFL lamps. The depths of the gap between positive column and phosphor screen are sensitively changed with the distribution of the electric charges on the phosphor particles in the screen. The depths of the gap are changed with the arrangement of the pure phosphor particles and charged particles by side by side [18]. There is no commercial equipment for the study on the electric charges on the phosphor particles of the FL lamps. You may find the surface conditions of the phosphor particle by the measurements of the hand-made instruments.

If the FL lamps are produced with the phosphor screen with the no electric 
charges that are the low voltage CL phosphor particles without inorganic binder, the depth of the gap will reduce to $4 \times 10^{-4} \mathrm{~m}$ [16] [18]. But the moving electrons in the internal electric circuit selective take the surface conduction on the phosphor screen, giving rise to no volume of the positive column in the lighted FL lamps. You must control the distribution of the electric charges on the surface of the phosphor particles in the screen for the practical FL lamps. The control of the electric charges on the phosphor particles in the FL lamps requires the special arrangement of the high resolution of the monitor CRTs and PL phosphor particles [19] [20]. You cannot make it with the established screen technologies of the phosphor screen in the FL lamps.

\section{A Prototype of Coil-EEFL Lamps by Conversion from CCFL Lamps in Outer Diameter of $3 \times 10^{-3} \mathrm{~m}$}

Fortunately, we have found the commercial cold-cathode FL (CCFL) lamps in the out diameter at $3 \times 10^{-3} \mathrm{~m}$ on the market. We like to know about commercial CCFL lamps.

\subsection{What Is CCFL Lamp?}

The commercial CCFL lamp in out diameter $3.2 \times 10^{-3} \mathrm{~m}$ (T-1) brilliantly and uniformly lights up, indicating the shallow gap less than $3 \times 10^{-4} \mathrm{~m}$. The producers of the CCFL lamps may find the phosphor screens with the try and error approach. Therefore, the phosphor screens of the commercial CCFL lamps in the diameter at $3.2 \times 10^{-3} \mathrm{~m}$ are not well controlled. The many commercial phosphor powders are contaminated with the crystallized residuals which are formed in the last drying process [19] [20]. Next important consideration is the numbers of phosphor particles in the phosphor screens. The numbers of the phosphor particles should be less than 3 layers. The commercial CCFL lamps in the diameter $3.2 \times 10^{-3} \mathrm{~m}(\mathrm{~T}-1)$ were the light source of the LCD display for the computers and TV sets before 2010 .

Here we must know what the CCFL lamp is. The metal cup electrodes (e.g., cold cathode, CC) set at the both ends of the CCFL lamps as the cathode and anode under the assumption that the CC cathode electrode directly emits the electrons into the Ar gas and the CC anode electrode directly corrects the arrived electrons. This is the hypotheses without the proof by the scientific evidence. In reality, the CC metal electrodes never emit the electrons into the Ar gas space and never correct the electrons from the Ar gas space. Actually, the CC electrodes form the heated spot at inside of the CC. We had made the handmade CCFL lamp for observation of the inside of the CC electrode. Figure 3 shows photograph of the tested CCFL lamp in the out diameter at $9.5 \times 10^{-3} \mathrm{~m}(\mathrm{~T}-3)$.

Figure 4 shows photograph of the inside of the CC electrode of the lighted CCFL lamp. As you may see in Figure 4, the inside wall of the CC electrode is covered with the thin insulating particles. Bottom of the inside metal cup has many small bear metal spots that are heated by the electron beam to the temperature above $600^{\circ} \mathrm{C}$. The volume of the heated Ar atoms is ionized by the electric 


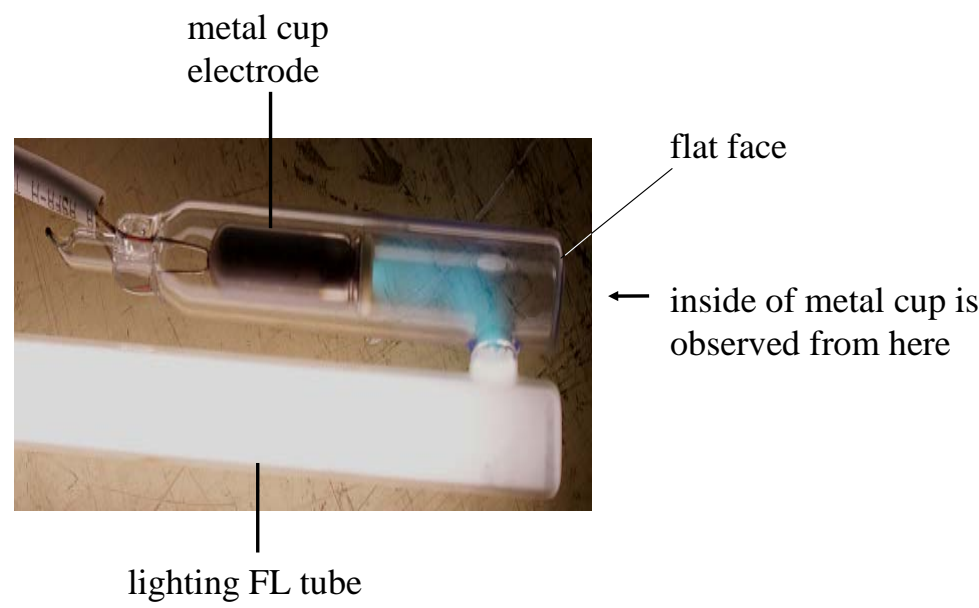

Figure 3. Photograph of lighted cold cathode FL lamp for observation of inside of cold-electrode.

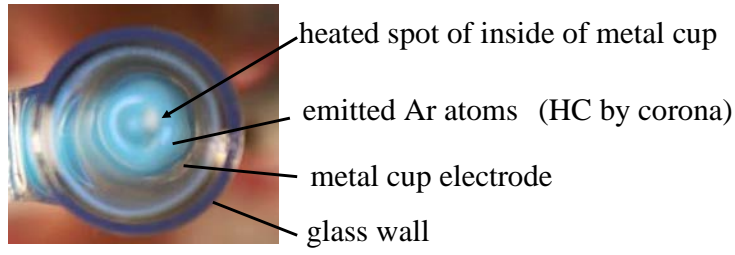

(a)

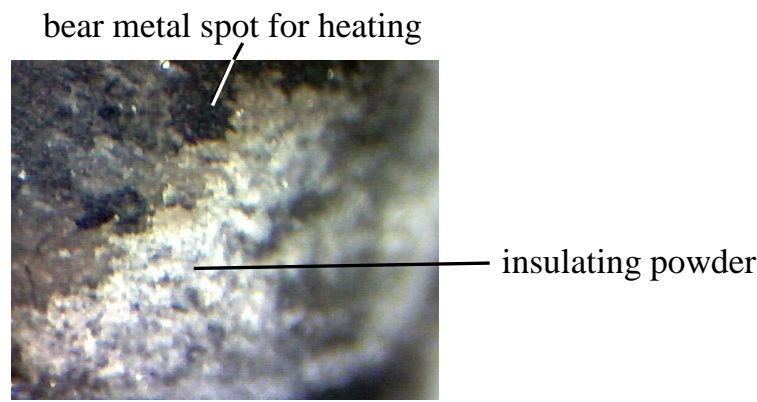

(b)

Figure 4. Photograph of inside of cold cathode of lighted CCFL lamp (a). Inside wall of CC cathode is roughly covered with insulating powder (b). There are many bear spots that are heated to high temperature for formation of volume of corona light.

field between the CC electrodes. The cold cathode is not the cold cathode. It is actually hotcathode. The CC electrodes pick up the induced AC current based on the $\mathrm{C}_{\mathrm{Ar}}$. Unfortunately, they have believed that the detected AC current by the $\mathrm{CC}$ electrodes corresponds to the electron flow in the Ar gas space. In reality, the $\mathrm{CC}$ electrodes at the both ends pick up the induced $\mathrm{AC}$ current from the $\mathrm{C}_{\mathrm{Ar}}$ in the operation, as illustrated in Figure 2. The amount of the induced AC current is around $0.5 \mathrm{~A}$. The induced $\mathrm{AC}$ current changes with the Ar gas pressures; high induced AC current with the high Ar gas pressure. 
The use of the CCFL lamps for the computers and TV sets has abandoned with the reason of the power hungry light source. If the CCFL lamps produce without metal cup electrodes, the CCFL lamp can change to the coil-EEFL lamp. The changed coil-EEFL lamps in parallel connection in any numbers can be operated with the $\mathrm{DC}$ driving circuit with $\mathrm{W}_{\mathrm{DC}}=0$. The coil-EEFL lamps in the any sizes will be the final power saving light source for the backlight of the LCD panel in any sizes from few $10^{-2} \mathrm{~m}$ diagonal to a few meters diagonal. The illuminance $\left(\mathrm{lm} \cdot \mathrm{m}^{-2}\right)$ of the coil-EEFL lamps can be increased with the Ar gas pressures and applied DC voltages with the $\mathrm{W}_{\mathrm{DC}}=0$. This is an interesting subject for whom considers the reduction of the electric power consumption of the LCD display panels. The details of the conversion of the commercial CCFL lamps to the coil-EEFL lamps will describe below:

\subsection{Prototype of Coil-EEFL Lamp Converted from CCFL Lamp}

Using the selected commercial CCFL lamps, we have the following experiments. From the analysis of the inside of the cup electrode as shown in Figure 4, the commercial CCFL lamps are light up with the volumes of the corona light in the inside of the electrodes. If it is so, the volume of the glow lights in the Ar gas space can be made with the electric field from the electrodes on the outer glass wall of the CCFL lamp. We have the set the electrodes on the outside glass wall of the commercial CCFL lamps by winding the lead wire in the $1 \times 10^{-3} \mathrm{~m}$ diameter with a few turns. This is the external coil electrode. For the security, the lead wires are covered with the plastic layer in the thickness in $5 \times 10^{-4} \mathrm{~m}$. Furthermore, the lead wires on the outer glass wall at the both ends are covered with the shrinkage plastic tube in order to avoid the arc discharge in the trapped air between the metal wire and glass wall. Then, the shrinkage plastic tubes heat up by the heated air before use. Thus, the CCFL lamp in $3 \times 10^{-3} \mathrm{~m}$ diameter converts to the coil-EEFL lamp. We have tried the cylinder electrodes on the outer glass wall. However, the cylinder electrodes sometimes make the trouble with the vacuum break of the coil-EEFL lamp by the arc discharge of the trapped air bubbles between cylinder electrode and outer glass tube.

We have applied the DC voltages to the external electrodes of the converted coil-EEFL lamp. The coil-EEFL lamp does not light up with the applied DC voltage below $0.95 \mathrm{kV}$. The coil-EEFL lamp has a threshold voltage for the light up. The threshold voltage is $1.0 \mathrm{kV}$ of the examined coil-EEF lamp. There is no appearance and disappearance voltage. The illuminance $\left(\mathrm{lm} \cdot \mathrm{m}^{-2}\right)$ of the coil-EEFL lamp increases with the applied DC voltages. Surprisingly, the coil-EEFL lamp brilliantly lights up with the zero electric power consumption, $\mathrm{W}_{\mathrm{DC}}=0$ at any supplied voltages above $1.0 \mathrm{kV}$. We have a prototype of the coil-EEFL lamp as the ideal incandescent lamp in our hand. Figure 5 shows the photograph of the lighted coil-EEFL lamp with the application of DC $=2 \mathrm{kV}$. The coil-EEFL lamp in Figure 5 does not have the shrinkage plastic tubes. Thus, we have a prototype of the coil-EEFL lamp that lights up with the zero DC power consumption, $\mathrm{W}_{\mathrm{DC}}$ $=0$. 


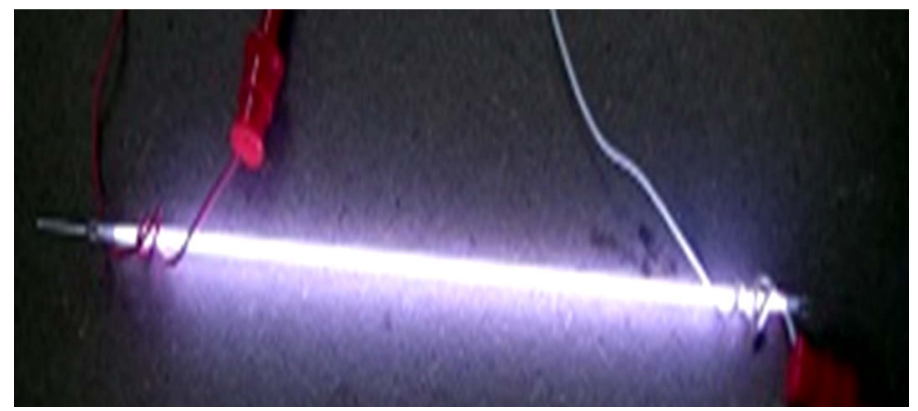

Figure 5. Lighted coil-EEFL lamp under DC driving circuit at $2 \mathrm{kV}$. EEFL lamp has converted from commercial CCFL lamp in $3 \times 10^{-3} \mathrm{~m}$ diameter.

The coil-EEFL lamps are also operated with the AC voltages above $1.0 \mathrm{kV}$ with $30 \mathrm{kHz}$. In this case, the EE detects the induced AC current caused by the synchronously polarized phosphor particles underneath the EE. The AC current by the polarized phosphor particles is one five of the AC current of the CCFL lamps. The luminance $\left(\mathrm{lm} \cdot \mathrm{m}^{-2}\right)$ of the coil-EEFL lamps under the AC operation is the same with the coil-EEFL lamps under the DC operation. For the contribution to the Green Energy Project by UN, the coil-EEFL lamps should be operated with the $\mathrm{DC}$ voltages with $\mathrm{W}_{\mathrm{DC}}=0$.

\subsection{Formation of Internal DC Electric Circuit in Coil-EEFL Lamp}

For the optimization of the coil-EEFL lamps, we have studied the details of the lighting mechanisms of the coil-EEFL lamps. Figure 6 schematically illustrates the lighting mechanisms of the coil-EEFL lamp. The glass tube is a good electric insulator, so that the electrons from the metal electrodes on the outer glass wall cannot penetrate through the glass wall. Consequently, the external driving circuit does not provide the electrons to the Ar gas space. Only electric field from the electrodes vertically penetrates through the thickness of the glass wall and reaches to the phosphor screen. So far as the phosphor screen is made with a few layers of the phosphor particles, the phosphor particles under the electrodes are polarized with the vertical electric field from the metal electrodes. If the phosphor screens are made with the layers thicker than 5 layers of the particles, the light output from the coil-EEFL lamps goes down with the numbers of the phosphor particles in the screen.

The polarized phosphor particles have the separated distribution of the charges in the inside of the phosphor particles. The positive charges $\left(\mathrm{Ar}^{1+}\right)$ gather up in front of the negative metal electrode. The negative charges $\left(\mathrm{e}^{-}\right)$in the polarized phosphor particles distribute to the Ar gas side. The electric field from the negative charges in the polarized phosphor particles extends to the Ar gas space. Then, the some volume of the Ar atoms in front of the polarized phosphor particles is ionized with the strong negative electric field from the polarized phosphor particles. The volume of the ionized Ar atoms is the volume of the glow light. The distribution of the electric charges in the volume of the glow 
DC electric source

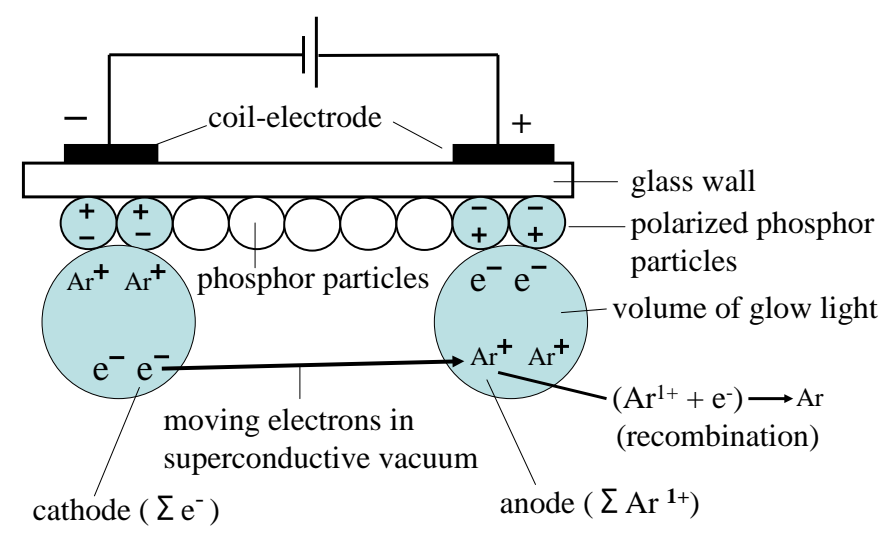

Figure 6. Schematic illustration of lighting mechanisms of coilEEFL lamp. The cathode of the coil-EEFL lamp is formed with $\Sigma \mathrm{e}^{-}$ and anode is formed with $\Sigma \mathrm{Ar}^{1+}$ in volume of the glow lights respectively.

light also separate to $\mathrm{Ar}^{1+}$ and $\mathrm{e}^{-}$. The accumulated negative charges $\left(\Sigma \mathrm{e}^{-}\right)$in the volume of the glow light act as the cathode of the internal electric circuit. Under the positive metal electrode, the accumulated positive charges $\left(\Sigma \mathrm{Ar}^{1+}\right)$ in the volume of glow light acts as the anode of the internal electric circuit. Thus the cathode and anode of the internal DC electric circuit are formed in the Ar gas space of the coil-EEFL lamp, without the supply of the electrons from the external electrodes. The $\mathrm{Ar}^{1+}$ and electrons in the volume of the glow light are invisible by the naked eyes. Fortunately, the $\mathrm{Ar}^{\star}$ emit the sky blue lights in the visible wavelengths. The $\mathrm{Ar}^{\star}$ atoms return to Ar atoms after the formation of $\mathrm{Ar}^{\star}$ within $10^{-6}$ seconds. Fortunately, the presence and thickness of the volume of the glow lights are monitored with the sky-blue lights from the $\mathrm{Ar}^{\star}$. The thickness of the volume of the glow light in the coil-EEFL lamp converted from the CCFL lamp is $3 \times 10^{-3} \mathrm{~m}$. The majorities in the volume of glow light are $\mathrm{Ar}^{1+}$ and free electrons; more than 50 times of the $\mathrm{Ar}^{*}$ [1] [2] [3] [13] [15].

The electron in the volume of the cathode may move on in the volume of the glow light under the $\mathrm{F}_{\mathrm{DC}}$. The moving electron under $\mathrm{F}_{\mathrm{DC}}$ may step out to the $\mathrm{Ar}$ gas at the nearby the volume of the glow light. The stepped electron may generate $\mathrm{Ar}^{1+}$ for the neutralization at the nearby volume. The neutralization of the negative electric field propagates to the entire Ar gas space with the speed of the electrons in the vacuum that is $10^{8} \mathrm{~m}$ per second. As shown in the photograph in Figure 5, the coil-EEFL lamp uniformly light up between cathode and anode in the internal electric circuit. Under the observation of the magnified lens $(\times 10)$, there is no discontinuous light (stripes) between cathode and anode, as the considered in the past study [7] [8] [9] [10] [11]. The coil-EEFL lamps light up with the moving electrons in the internal DC electric circuit, without the supply of the electrons from the EE on the glass wall. This means the coil-EEFL lamps light up with no electric power consumption of the external DC electric circuit. The users of the coil-EEFL lamps do not pay the electricity to the electric suppliers for the 
lighting. The coil-EEFL lamp is a miracle lighting source for the users.

\subsection{Direct Evidence of Superconductive Vacuum in Lighted FL Lamps}

As already mentioned, the vacuum between floating Ar atoms in the FL lamps forms the superconductive vacuum at above room temperatures. The superconductive vacuum for moving electrons is a great advantage of the lighted FL lamps. The moving electrons in the superconductive vacuum do not lose the kinetic energy by Joule Heat. However, we cannot detect the DC current in the inside of the coil-EEFL lamp. We take the needle cathode and anode in the glass tube with the Ar gas at $8.7 \times 10^{3} \mathrm{~Pa}$ (= 50 Torr) that is equivalent with the Ar gas pressure of the CCFL lamps. The cathode and anode have the DC electric current meters, respectively. Figure 7 shows the experimental results by using needle cathode and anode electrode.

As the DC applied voltages on the needle metal electrodes are gradually increased from DC 100 volt, the testing tube does not have the volume of the glow lights below $0.95 \mathrm{kV}$. The Ar gas space between the electrodes is the electric insulator below $0.95 \mathrm{kV}$. By the application of the DC $1.0 \mathrm{kV}$ to the cathode and anode, the needle electrodes at the both sides are suddenly covered with the volume of the glow lights. Accordingly, the testing glass tube lights up with the sky-blue light. We have observed the curious results with the application of the DC voltages above $1 \mathrm{kV}$. As the applied voltages to the needle electrodes gradually increase to $10 \mathrm{kV}$ from $1.0 \mathrm{kV}$, the needle electrodes hold the constant DC voltage at $1.0 \mathrm{kV}$. But the DC current meters at the electrodes vertically increase with the applied voltages to the electrodes as shown in Figure 7. The size of the volume of the glow light on the needle electrodes does not change with the applied DC voltages. The results indicate us that the electrons do not come from the sharp point of the needle electrodes. The whole area of the needle electrodes is covered with the volume of the glow light. The volume of the glow light emits

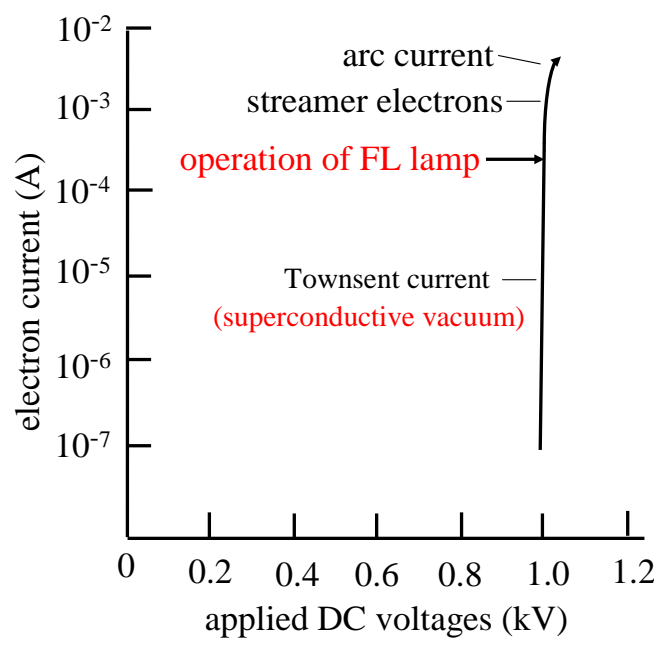

Figure 7. DC electric current in internal DC electric circuit of FL lamps. 
the electrons to the Ar gas space from somewhere in the volume of the glow light. With this reason, the sharp point of the needle electrodes do not rounded with the Joule Heat. The sharpness of the needle electrodes reserves with the volume of the glow light. The results of Figure 7 are concealed with the study on the HCFL and CCFL lamps which are operated with the AC external driving circuit. They only detect the large amount of the induced AC current that is not related with the moving electrons in the inside of the FL lamps. We have found the stability of the volume of the glow light in the operation of the coil-EEFL lamps.

The vertical increase in the DC currents at $1.0 \mathrm{kV}$ in Figure 7 is a direct evidence of the existence of the superconductive vacuum in the Ar gas space between Ar atoms in the lighted FL lamps. The moving electrons in the superconductive vacuum do not have the electric resistance $(R)$, so that there is no voltage drop with $\mathrm{V}=R \mathrm{I}=0$. This is the reason that we obtain the vertical VI curve as shown in Figure 7. The results in the Figure 7 provide us the very important information on the study of the FL lamps. The results in Figure 7 do not change with the Ar gas pressures below $10^{4} \mathrm{~Pa}$ (= 70 Torr) that we have studied. The numbers of the ionized $\mathrm{Ar}^{1+}$ and electrons in the volume of the glow light increase with the Ar gas pressures. The formation of $\mathrm{Ar}^{1+}$ releases the heat in the volume of the glow light by the change in the entropy. Therefore, the temperatures of the positive column increase with the Ar gas pressures. The Hg droplets on the phosphor screen in the coil-EEFL lamps are heated by the thermal radiation from positive column. The numbers of the evaporated $\mathrm{Hg}$ atoms from the Hg droplets on the phosphor screen exponentially increase with the temperatures on the $\mathrm{Hg}$ droplets. The illuminance $\left(\mathrm{lm} \cdot \mathrm{m}^{-2}\right)$ of the coil-EEFL lamps will increase with the vaporized $\mathrm{Hg}$ atoms in the positive column. The upper limitation of the Ar gas pressures will given by the heat protection of the coil-EEFL lamps. It should note that HCFL lamps cannot increase the Ar gas pressures with the linear increase in the induced AC current at the electrodes. The only coil-EEFL lamps increase the illuminance $\left(\mathrm{lm} \cdot \mathrm{m}^{-2}\right)$ with the Ar gas pressures. The increase in the illuminance with the Ar gas pressures is another advantage of the coil-EEFL lamps.

The results in Figure 7 had already obtained by J. S. Townsend on 1903, but he could not analyze the curve as the superconductive vacuum between $\mathrm{Ar}$ atoms in the lighted FL lamps at the room temperature. He gave the name as the Townsend electric current as indicate in Figure 7. We have found that the Townsend electric current is the electric current in the superconductive vacuum between the floating Ar atoms. The results shown in Figure 7 had used in the practical DC voltage regulation tubes before the development of the solid-state voltage regulation devices. The study on the voltage regulation tubes did not find the superconductive vacuum in the Ar gas space.

\subsection{Voltage Dependence Curve of Coil-EEFL Lamp}

By the observation of the results in Figure 7, we have a curiosity of the illumin- 
ance $\left(\mathrm{lm} \cdot \mathrm{m}^{-2}\right)$ as a function of the DC applied voltages. Figure 8 shows the relative illuminance $\left(\mathrm{lm} \cdot \mathrm{m}^{-2}\right)$ of the coil-EEFL lamp as a function of the applied DC voltages $(\mathrm{kV})$ to the EEs. The experiments are made with the series connection of two DC driving circuits at which the connection area of the two DC driving circuits has the grand, as shown in Figure 8. The illuminance $\left(\mathrm{lm} \cdot \mathrm{m}^{-2}\right)$ of the coil-EEFL tubes shown in Figure 5 linearly increases with the applied DC voltages. By referring of the results in Figure 7, the voltage between the cathode and anode of the internal DC driving circuit holds the constant DC voltage at 1.0 $\mathrm{kV}$. The linear increase in the illuminance $\left(\mathrm{lm} \cdot \mathrm{m}^{-2}\right)$ with the applied voltages in Figure 8 is caused by the linear increase in the numbers of the moving electrons in the given coil-EEFL lamps. The illuminance $\left(\mathrm{lm} \cdot \mathrm{m}^{-2}\right)$ of the coil-EEFL lamps is given by the $\eta_{\mathrm{q}} \times$ (numbers of moving electrons) in the positive column in the given FL lamp. Naturally, the numbers of the $\mathrm{Ar}^{1+}$ in the positive column linearly increase with the numbers of the moving electrons. The formation of the $\mathrm{Ar}^{1+}$ releases the heat in the positive column by the change in the entropy. The thermal radiation from the heated positive column heats up the $\mathrm{Hg}$ droplets on the phosphor screen for the evaporation of the $\mathrm{Hg}$ atoms into the positive column. The presence of the $\mathrm{Ar}^{1+}$ is a necessary condition of the lighted FL lamps. $\Sigma \mathrm{Ar}^{1+}$ forms the $\mathrm{C}_{\mathrm{Ar}}$ under the $\mathrm{AC}$ driving circuit. Under the DC operation, the electrodes never pick up the induced current from the $\mathrm{C}_{\mathrm{Ar}}$. The coil-EEFL lamps should be operated with the DC voltages higher than $1 \mathrm{kV}$.

\section{Coil-EEFL Lamp Converted from Commercial $40 \mathrm{~W}$-HCFL Lamps}

We have studied the basics of the lighting mechanisms of the coil-EEFL lamps converted from the CCFL lamps in the outer diameter of $3.2 \times 10^{-3} \mathrm{~m}$. The experimental results of the coil-EEFL lamps do not change with the diameters of the FL lamps. With the curiosity, we have converted the commercial $40 \mathrm{~W}$-HCFL lamps of the outer diameter $3.2 \times 10^{-2} \mathrm{~m}$ (T-10) with $1.0 \mathrm{~m}$ long. The inner diameter is $3.0 \times 10^{-2} \mathrm{~m}$. We have converted two kinds of the $40 \mathrm{~W}$-HCFL lamps to the coil-EEFL lamps. One is new commercial $40 \mathrm{~W}$-HCFL lamp from the store. Other is the life-terminated 40W-HCFLlamp that has taken from garbage yard. The both converted coil-EEFL lamps light up with the nearly equal illuminance with the application of the DC voltage at $6 \mathrm{kV}$ to the $\mathrm{EE}$ on the outer wall of the HCFL lamps. Figure 9 shows photograph of the lighted coil-EEFL lamps.

\subsection{RemarKable Reduction of Pollution Level on Grand by Coil-EEFL Lamps}

The photograph of the life-terminated HCFL lamp shows the darkness at around the W-filament coil, indicating that the life termination of the HCFL lamp is caused by the cut-off of the heated bear metal spot of the $\mathrm{W}$-filament coil by the evaporation. The cut-off of the $\mathrm{W}$-filament coil determines the operation life of 


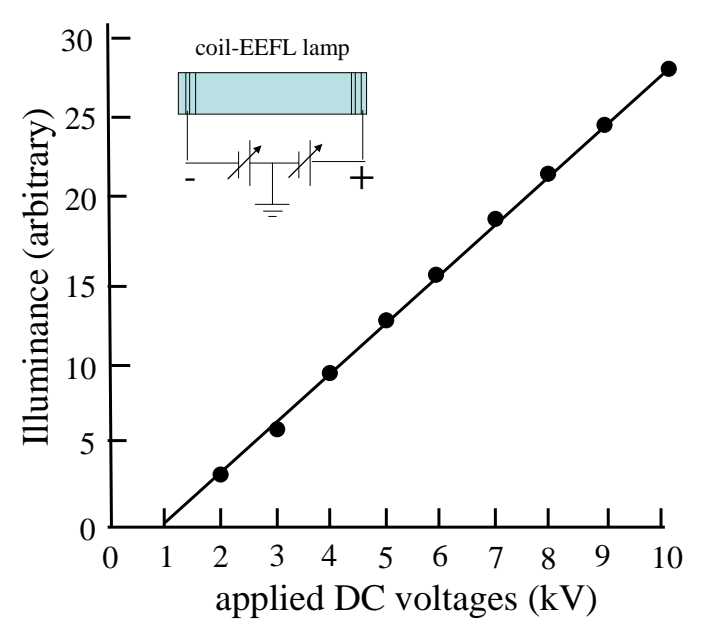

Figure 8. Illuminance $\left(\mathrm{lm} \cdot \mathrm{m}^{-2}\right)$ of coil-EEFL lamp as a function of applied DC voltages on electrodes.

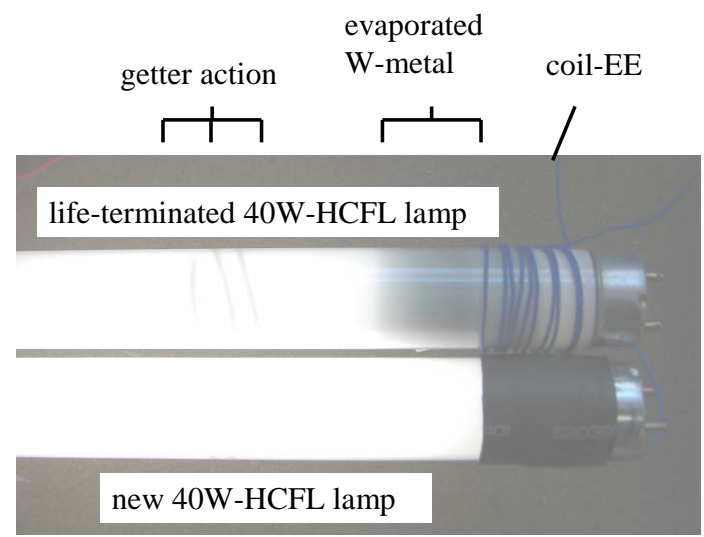

Figure 9. Photograph of lighted coil-EEFL lamps converted from $40 \mathrm{~W}$-HCFL lamps. Above photograph has converted from scraped $40 \mathrm{~W}$-HCFL lamp. Below photograph has converted from new $40 \mathrm{~W}$ HCFL lamps.

the commercial HCFL lamps gives the averaged operation life of around $10^{4}$ hours. The life-terminated HCFL lamps holds essential parts as the FL lamps. They are a) Ar gas pressures, b) $\mathrm{Hg}$ droplets, and c) phosphor screen as the transducer of the UV lights to the visible lights as the illumination source. The results in Figure 9 indicate that the life-terminated $40 \mathrm{~W}$-HCFL lamp is perfectly revived with the setting of the coil-EEs on the outer glass wall. The revived coil-EEFL lamp emits the similar illuminance $\left(\mathrm{lm} \cdot \mathrm{m}^{-2}\right)$ with the coil-EEFL lamp converted from the new HCFL lamp.

The results of the life-terminated HCFL lamp in Figure 9 indicate an important massage for us. The revived coil-EEFL lamp from the scrapped $40 \mathrm{~W}$-HCFL lamp does not loosen the Ar atoms in the operation, promising the long operation life, longer than $10^{6}$ hours. If the coil-EEFL lamp lights up for 24 hours per day, the operation hours per year is $9 \times 10^{3}$ hours. The operation hours for 100 
years will be $10^{6}$ hours. The photograph (above) in Figure 9 provides the important massages that we may remarkably reduce the pollution level on the grand of the Earth by lighting of coil-EEFL lamps. The reduction level of the pollution on the grand by the coil-EEFL lamps will go down to more than one hundreds of the present HCFL lamps. This is the significantly low level for the consideration of the pollution on the grand of the Earth by the coil-EEFL lamps.

\subsection{Illuminance of Coil-EEFL Lamps Converted from Commercial HCFL Lamps}

The next consideration is the illuminance $\left(\mathrm{lm} \cdot \mathrm{m}^{-2}\right)$ of the converted coil-EEFL lamps from the $40 \mathrm{~W}$-HCFL lamps. The converted coil-EEFL lamp from the scrapped $40 \mathrm{~W}$-HCFL lamp miraculously brilliantly lights up with the similar illuminance $\left(\mathrm{lm} \cdot \mathrm{m}^{-2}\right)$ with the coil-EEFL lamp converted from the new HCFL lamp, except for at around the $\mathrm{W}$-filament coils. The scrapped HCFL lamps just lost the cathode and anode of the internal electric circuit that are the volumes of the HTACS [14]. The conditions of the Ar gas pressures, Hg droplets, and the phosphor screen remain as the similar with the new $40 \mathrm{~W}$-HCFL lamps. However, the optimized conditions of the coil-EEFL lamps in $3.2 \times 10^{-2} \mathrm{~m}$ differ from the required conditions of the $40 \mathrm{~W}$-HCFL lamps. The largest differences are a) the electric charges on the phosphor particles in the screens, and b) the Ar gas pressures. The electric charges on the phosphor particles in the screen will describe in 5-3.

Here we discuss about the Ar gas pressures. The $40 \mathrm{~W}$-HCFL lamps contain only $\mathrm{Ar}$ gas pressure at around $930 \mathrm{~Pa}$ (= 7 Torr). This is because the electric power consumptions $\left(\mathrm{W}_{\mathrm{act}}\right)$ of the $40 \mathrm{~W}$-HCFL lamps have determined by a) the $\mathrm{AC}$ induced current from the $\mathrm{C}_{\mathrm{Ar}}$ and $\mathrm{b}$ ) the $\mathrm{AC}$ applied voltages at the electrodes of the external AC driving circuit. Since the EEs of the coil-EEFL lamps under the DC external circuit never pick up the induced AC current from the $\mathrm{C}_{\mathrm{Ar}}$, the coil-EEFL lamps do not have the limitation of the Ar gas pressures. The temperatures of the positive column determine the numbers of the evaporated $\mathrm{Hg}$ atoms in the positive column; high $\mathrm{Hg}$ atoms with the high Ar gas pressures in the positive column. The heat source of the positive column is only the ionization of the Ar atoms by the change in the entropy; the high temperatures with the high Ar gas pressures. Therefore, the high illuminance $\left(\mathrm{lm} \cdot \mathrm{m}^{-2}\right)$ of the coil-EEFL lamps in $3.2 \times 10^{-2} \mathrm{~m}$ diameter will be obtained with the high Ar gas pressures, e. g., higher than $6650 \mathrm{~Pa}$ (= 50 Torr) that is the equivalent with the Ar gas pressure of the CCFL lamps.

As described in Section 4, the commercial CCFL lamps in the outer diameter at $3.2 \times 10^{-3} \mathrm{~m}$ are produced with the Ar gas pressures at above $6650 \mathrm{~Pa}(=50$ Torr). The producers of the CCFL lamps do not claim the selection of the phosphor particles in the screen. Possibly, the producers of the CCFL lamps handle the electric charges on the surfaces of the phosphor particles in the screen. They also have optimized with the thin phosphor screens, possibly at around 3 layers of the phosphor particles. The coil-EEFL lamps have the same illuminance of the 
CCFL lamps. From the study on the coil-EEFL lamps in the $3.2 \times 10^{-3} \mathrm{~m}$ diameter, we have tried to increase the Ar gas pressures of the coil-EEFL lamps in the $3.2 \times 10^{-2} \mathrm{~m}$ diameter. Unfortunately, we could not find the adequate production facilities of the FL lamps wider than $2.2 \times 10^{-2} \mathrm{~m}$ (T-7) with the Ar gas pressures higher than $1330 \mathrm{~Pa}$ (=10 Torr). The inside of the production facilities are heavily contaminated with the oil-vapor of the rotary pumps. With this reason, the increase in the Ar gas pressures of the coil-EEFL lamps wider than $2.2 \times 10^{-2} \mathrm{~m}$ remains as a future study by someone else. He will surely have the illuminance (more than $500 \mathrm{~lm} \cdot \mathrm{m}^{-2}$ ) of the coil-EEFL lamps wider than $2 \times 10^{-2} \mathrm{~m}$ with the Ar gas pressures higher than $7000 \mathrm{~Pa}(\approx 50$ Torr $)$ that give the high illuminance with the long operation life.

\subsection{Commercial $40 \mathrm{~W}$-HCFL Lamps have Gaps Deeper than $3 \times$ $10^{-3} \mathrm{~m}$}

The commercial $40 \mathrm{~W}$-HCFL lamps have another serious problem. The problem is the depth of the gap between phosphor screen and positive column. The depths of the gap of the commercial $40 \mathrm{~W}$-HCFL lamps are deeper than $3 \times 10^{-3}$ m. The deep gap contains the unexcited $\mathrm{Hg}$ atoms that optically absorb the UV lights from the positive column before reaching to the phosphor screen. Furthermore, the Ar gas in the gap acts as the heat resistance between positive column and phosphor screen. The UV light source in the FL lamps is the excited $\mathrm{Hg}$ atoms that evaporate from the $\mathrm{Hg}$ droplets on the phosphor screen. The heat source in the FL lamps is only the ionization of the Ar atoms by the moving electrons in the positive column, by the change in the entropy.

The moving electrons in the positive column never step in the Ar gas in the gap. The $\mathrm{Hg}$ atoms in the positive column are excited by the moving electrons. The excited $\mathrm{Hg}$ atoms in the positive column emit the UV lights at mainly 254 $\mathrm{nm}$ with a weak at $187 \mathrm{~nm}$. The transitions of the UV lights are respectively assigned from the excited ${ }^{3} \mathrm{P}_{1}$ and ${ }^{1} \mathrm{P}_{1}$ to grand state ${ }^{6} \mathrm{~S}_{0}$. The gap contains unexcited $\mathrm{Hg}$ atoms that fill up the electrons in the grand state ${ }^{6} \mathrm{~S}_{0}$. The $\mathrm{Hg}$ atoms in the gap efficiently absorb the UV lights from the positive column with the resonance absorptions before reaching to the phosphor screen. We may calculate the absorbed UV lights by the $\mathrm{Hg}$ atoms in the gap of the commercial HCFL lamps with the outer diameter of $3.2 \times 10^{-2} \mathrm{~m}$ with $1 \mathrm{~m}$ long.

The thickness of glass tube is $1 \times 10^{-3} \mathrm{~m}$. The inner diameter of the FL tube is $3.0 \times 10^{-2} \mathrm{~m}\left\{=(3.2-0.2) \times 10^{-2} \mathrm{~m}\right\}$. The inner volume $\left(\mathrm{V}_{\text {tube }}\right)$ of the HCFL lamps is given by $\left(\pi r^{2} \times 1 \mathrm{~m}\right)$ where $r$ is radius. The calculated $V_{\text {tube }}$ is $7.0 \times 10^{-4}$ $\mathrm{m}^{3}\left\{=\left(1.5 \times 10^{-2} \mathrm{~m}\right)^{2} \times \pi \times 1 \mathrm{~m}\right\}$. We may determine the depth of the gap of the 40W-HCFL lamp, by the partial removal of the phosphor screen. The depth of the gap is $3 \times 10^{-3} \mathrm{~m}$. Total thickness of the gaps in the FL tube is $6 \times 10^{-3} \mathrm{~m}$. The diameter of the positive column is $2.4 \times 10^{-2} \mathrm{~m}\left\{=(3.0-0.6) \times 10^{-2} \mathrm{~m}\right\}$. Then we may calculate the volume of the positive column, $\mathrm{V}_{\text {posi }}=4.5 \times 10^{-4} \mathrm{~m}^{3}\{=(2.4 \times$ $\left.\left.10^{-2} \times 2^{-1}\right)^{2} \times \pi \times 1 \mathrm{~m}\right\}$. The volume of the gap, $\mathrm{V}_{\text {gap }}$, is calculated as $2.5 \times 10^{-4} \mathrm{~m}^{3}$ $(=7.0-4.5) \times 10^{-4} \mathrm{~m}^{3}$. The ratio of $\mathrm{V}_{\text {posi }}$ per $\mathrm{V}_{\text {tube }}$ is given by $0.64\{=(4.5) \times(7.0)$ 
$\left.{ }^{-1}\right\}$. The $\mathrm{V}_{\text {gap }}$ per $\mathrm{V}_{\text {tube }}$ is $0.36\left\{=2.5 \times(7.0)^{-1}\right\}$. The ratio of $\mathrm{V}_{\text {gap }}$ per $\mathrm{V}_{\text {pos }}$ is 0.56 . The calculations give us the important information in the study on the performance of the $40 \mathrm{~W}$-HCFL lamps.

The origin of the lights in the FL lamps are the UV lights from the excited $\mathrm{Hg}$ atoms $\left(\mathrm{Hg}^{*}\right)$. The $\mathrm{Hg}^{*}$ are only made in the positive column where the electrons move on Ar gas space between the cathode and anode of the internal DC electric circuit. The emitted UV lights in the positive column must penetrate through the volume of the gap before reaching to the phosphor screen. The gap contains unexcited $\mathrm{Hg}$ atoms that efficiently absorb the UV lights with the resonance absorption. This means that $56 \%$ of the emitted UV lights in the positive column are optically absorbed by the unexcited $\mathrm{Hg}$ atoms in the gap. Only $44 \%$ ( $=1.0-$ $0.56 \%$ ) of the UV lights emitted UV lights in the positive column reach on the phosphor screen. The reached UV lights on the phosphor screen transduce to the visible lights with the $\eta_{\mathrm{q}} \approx 1.0$. The results clearly inform us that the commercial $40 \mathrm{~W}$-HCFL lamps light up with $44 \%$ of the generated UV lights in the positive column. If the depth of the gap of the commercial $40 \mathrm{~W}$-HCFL lamps reduces to $5 \times 10^{-4} \mathrm{~m}$ from the $3 \times 10^{-3} \mathrm{~m}$, the loss of the UV lights by the self-absorption in the gap will be down to $8 \%$. Logically, the commercial 40 W-HCFL lamps may have the double illuminance $\left(\mathrm{lm} \cdot \mathrm{m}^{-2}\right)$ with the reduction of the depth of the gap to $5 \times 10^{-4} \mathrm{~m}$ from the $3 \times 10^{-3} \mathrm{~m}$. However, there is no report on the attractive subject for the improvement of the illuminance $\left(\mathrm{lm} \cdot \mathrm{m}^{-2}\right)$ in the last 90 years. This is because there is a difficulty of the determination of the depths of the gap of the lighted HCFL lamps. We have found a way of a semi-quantitative determination of the depths of the gap between positive column and phosphor screen. That is the measurements of the build-up curves of the illuminance of the coil-EEFL lamps in the Ulbricht Sphere. Figure 10 shows the build-up curves of two coil-EEFL lamps. Figure $10(\mathrm{~A})$ is the build-up curve of the coil-EEFL lamp with the shallow gap at $3 \times 10^{-4} \mathrm{~m}$. Figure $10(\mathrm{~B})$ is the build-up curve of coil-EEFL lamp converted from the $40 \mathrm{~W}$-HCFL lamp that has the gap at $3 \times 10^{-3} \mathrm{~m}$.

It should note that the illuminance $\left(\mathrm{lm} \cdot \mathrm{m}^{-2}\right)$ of the $40 \mathrm{~W}$-HCFL lamps will increase with the reduction of the depth of the gap to $3 \times 10^{-4} \mathrm{~m}$, but the reduction of the gap increase the numbers of $\mathrm{Ar}^{1+}$ in the positive column of the lighted 40 W-HCFL lamps. The AC induced current at the electrodes also increase to double. In the past 90 years, they believed that the $\mathrm{W}_{\text {act }}$ determined at the electrodes relates to the generation energy of the lights of the HCFL lamps. In their study, we have found that the $\mathrm{W}_{\text {act }}$ at the electrodes is not related with the generation energy of the light. The determined $\mathrm{W}_{\text {act }}$ is actually the active AC power consumption of the $\mathrm{C}_{\mathrm{Ar}}$.

It should note again that the coil-EEFL lamps under the operation by the DC electric circuit never pick up the $\mathrm{AC}$ induced current from the $\mathrm{C}_{\mathrm{Ar}}$. The illuminance $\left(\mathrm{lm} \cdot \mathrm{m}^{-2}\right)$ of the coil-EEFL lamps simply increase to double illuminance by the reduction of the depth of the gap. However, we have faced a very hard time to find the experimental facilities. We cannot find the experimental facilities for 


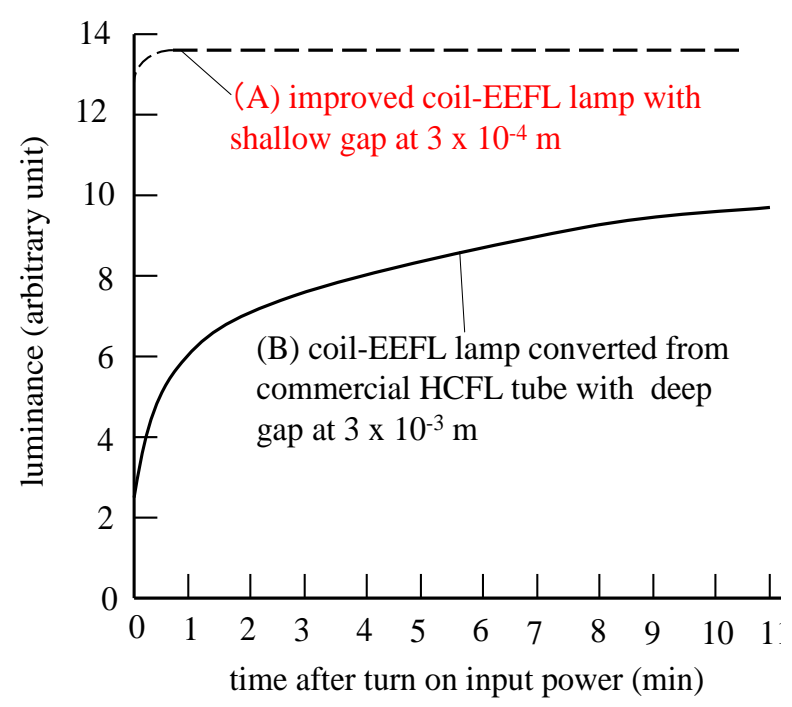

Figure 10. Build-up curves of shallow gap $\left(3 \times 10^{-4} \mathrm{~m}\right)$ of coil-EEFL lamp in diameter at $3.2 \times 10^{-3} \mathrm{~m}(\mathrm{~A})$ and deep gap $\left(3 \times 10^{-3} \mathrm{~m}\right)$ of coil-EEFL lamp converted from commercial $40 \mathrm{~W}$-HCFL lamp.

the increase in the Ar gas pressures and the reduction of the depth of the gap between positive column and phosphor screen in the commercial $40 \mathrm{~W}$-HCFL lamps. The experiments for the increase of the Ar gas pressures with the practical coil-EEFL lamps with the wide diameters may be made by someone else in near future.

Figure 11 shows, as the example, photograph that the lighted 10 coil-EEFL lamps in the parallel connection under the application of the DC $4 \mathrm{kV}$ to the EEs on outer glass wall which the EEs are covered with the thermally shrinking plastic tubes. The coil-EEFL lamps are converted from the commercial $40 \mathrm{~W}$-HCFL lamps in diameter of $3.2 \times 10^{-2} \mathrm{~m}$ with $1.0 \mathrm{~m}$ long. Two DC electric circuits are used for the driving circuit and center of the two DC circuits has grounded, as shown in Figure 8. The total illuminance of the 10 coil-EEFL lamps in the parallel connection is $1800\left(\mathrm{~lm} \cdot \mathrm{m}^{-2}\right)$ that comfortably illuminate the $6 \mathrm{~m}^{2}$ room with the daytime scenery under slightly overcastting sky. The power consumption of the $\mathrm{DC}$ driving circuit is $\mathrm{W}_{\mathrm{DC}}=0$. It should note that the Hg droplets are on the phosphor screen on internal wall of the coil-EEFL lamps. The temperatures of the Hg droplets in the coil-EEFL lamps are cooled with the air convection at room temperature in the room. If the coil-EEFL lamps set in the vacuum-sealed container, the temperature of the $\mathrm{Hg}$ droplets on the phosphor screen will be equivalent temperature with the positive column, resulting in the high illuminance $\left(\mathrm{lm} \cdot \mathrm{m}^{2}\right)$ [2] [3] [15]. The features of the lighting mechanisms of the coil-EEFL lamps are generated in the vacuum-volume of the vacuum-sealed glass tube, giving rise to the independence of the temperatures and humidity of the room. Then, it can say that the coil-EEFL lamps have the superior advantages over other incandescent lamps, like as LED lamps. 


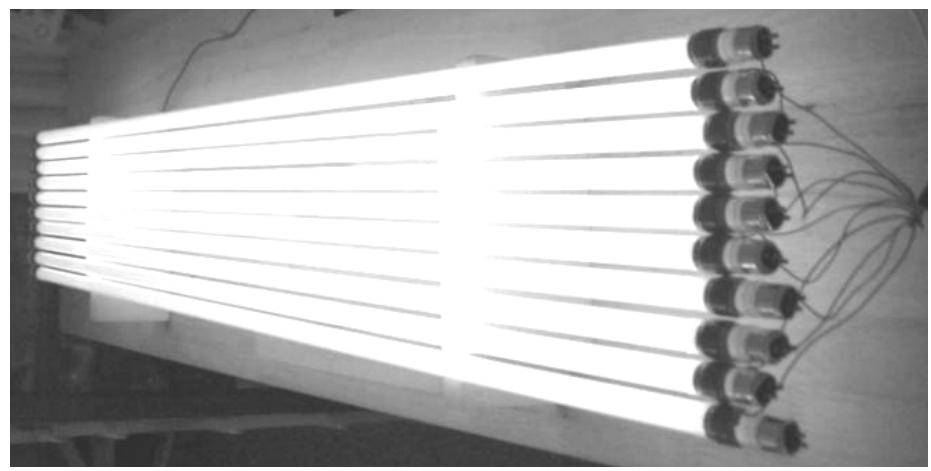

Figure 11. Photograph of lighted 10 coil-EEFL lamps in parallel connection under DC electric circuit at $4 \mathrm{kV}$ with $\mathrm{W}_{\mathrm{DC}}=0$. Coil-EEFL lamps have converted from commercial $40 \mathrm{~W}$-HCFL lamps in outer diameter of $3.2 \times 10^{-2} \mathrm{~m}$ and $1.0 \mathrm{~m}$ long.

\section{Safe of Hg Atoms in Production of FL Lamps}

Here is an action against the production of the FL tubes on the world with the use of the Minamata disease. The Japanese Government had ordered the termination of the production of the FL lamps in Japan on 2014 with the antipollution of the $\mathrm{Hg}$ by using the Minamata disease. Their action lacks the basics of the biological science. The living matters on the Earth do not directly take the metallic atom (e.g. Hg droplets) in the body. The necessary of the metallic atoms for the disease are in the organic compounds. The Minamata disease is caused by the uncontrolled drain of the organic compound of the methane mercury $\left(\mathrm{CH}_{4} \mathrm{Hg}\right)$ solution from the chemical factory to the sea water in Minamata Bay. If the Japanese Government had controlled the drain of the organic $\mathrm{CH}_{4} \mathrm{Hg}$ solution to the sea water from the starting of the chemical factory, the Minamata disease never happened in the small fishing villages at Minamata Bay. But the Japanese Government did not do it. There is no report from the industrialized countries in USA and Europe about the disease of the organic $\mathrm{CH}_{4} \mathrm{Hg}$ solution from the similar and larger chemical factories that use the $\mathrm{CH}_{4} \mathrm{Hg}$ catalysis. This is because the Governments in the USA and Europe well control the drain of the organic $\mathrm{CH}_{4} \mathrm{Hg}$ solution to the rivers. Only Japanese Government has the responsibility on the Minamata disease with no control of the drain of the organic $\mathrm{CH}_{4} \mathrm{Hg}$ solution to the Minamata Bay. It is clear that the Minamata disease has responded on the Japanese Government by the out control of the drain of the organic $\mathrm{CH}_{4} \mathrm{Hg}$ solution from the factory.

The $\mathrm{Hg}$ metal has the melting temperature at $-39^{\circ} \mathrm{C}$. The surface tension of melted $\mathrm{Hg}$ atoms at room temperature is $4.6 \times 10^{6}$ dyne per $\mathrm{m}$ that is very high surface tension. The small amount of the $\mathrm{Hg}$ metal at the room temper forms the droplet. The evaporation of the $\mathrm{Hg}$ droplets at the room temperature is $0.1 \mathrm{~Pa}$ $\left(10^{-3}\right.$ Torr). The Hg droplets has the density of $1.3 \mathrm{~kg} \cdot \mathrm{per} \cdot \mathrm{m}^{3}$ (= $\left.13 \mathrm{~g} \cdot \mathrm{per} \cdot \mathrm{cm}^{3}\right)$. The human society has used the $\mathrm{Hg}$ droplets as the useful material for more than 3000 years. But there was no report of the $\mathrm{Hg}$ disease like as the Minesota disease. 
We have found the followings. The Minamata disease was limited in the fishing villages, and was not the residents in the Minamata City. Why the Minamata disease was limited in the small fishing villages? The disease by the catalytic $\mathrm{CH}_{4} \mathrm{Hg}$ solution in the fishing village occurs with the organic cycles in the living body on the Earth. As a large amount of the organic $\mathrm{CH}_{4} \mathrm{Hg}$ solution discharges to the sea water in the Minamata Bay, the organic $\mathrm{CH}_{4} \mathrm{Hg}$ float in the sea water. The bacteria in the sea water first takes the floating organic $\mathrm{CH}_{4} \mathrm{Hg}$ compounds in to the cell of the bacteria. The bacteria never directly take the $\mathrm{Hg}$ atoms from the sea water. As the small fishes in the sea eat the contaminated bacteria, the organic Hg selectively concentrates in the brain and innards of the small fish. The meats of the small fish are not contaminated with the organic Hg. When the mother in the fishing villages eats the small fishes without removal of the head and innards of the fishes, her body is contaminated, but the mother does not have the serious trouble in the daily activity. When the mother is pregnant, the fetus in early stage selectively receives the contaminated organic $\mathrm{Hg}$ from the mother. The brain of the fetus is seriously damaged by the received organic $\mathrm{Hg}$, like as case of the Ziga Virus. The Minamata disease is limited as the new born babies. The residents in Minamata city, who eat the meets of the large fishes with the removal of the head and innards, never have the Minamata disease. If the Japanese Government controls the drain of the organic $\mathrm{CH}_{4} \mathrm{Hg}$ solution from the factory at early stage, the Minamata disease never happened in the fishing villages.

The FL lamps had invented more than 90 years ago. Each FL tubes use the small amount of inorganic $\mathrm{Hg}$ droplets (mg order) in the mass production of the FL lamps. The FL tubes never use the organic Hg compounds. Since then, the annual production volume was more than multimillions each year for 80 years. There is no report of the disease by the $\mathrm{Hg}$ droplets on the world, because the FL lamps use the melted $\mathrm{Hg}$ metal droplets in mg each. The melted $\mathrm{Hg}$ metal and $\mathrm{Hg}$ ingots (amalgam) had used in the human society for more than three thousand years. There is no report like as the Minamata disease.

Now it is clear that the Japanese Government has the responsibility to the Minamata disease. According to the biological science, the Japanese Government cannot claim the unsafe of the Hg droplets in the FL tubes as the poison of the human body, using the Minamata disease. The organic bacteria are not involved in the production of the FL lamps. The Hg droplets in the FL lamps quite differ from the catalytic $\mathrm{CH}_{4} \mathrm{Hg}$ solution. The regulation of the FL lamps by the Japanese Government using the Minamata disease is unacceptable as the biological science. The coil-EEFL lamps are the necessary illumination source for the Green Energy Project of COP (conference of particles) with the electric power consumption $\mathrm{W}_{\mathrm{DC}}=0$ and extremely long operation life longer than $10^{6}$ hours.

\section{Conclusion}

We have studies the coil-EEFL lamps as the advanced incandescent lamp for the contribution to the Green Energy Project of UN. The Ar atoms in the FL lamps 
float in the vacuum with the large separation distance at $10^{-6} \mathrm{~m}$. The FL lamps provide the superconductive vacuum at the temperatures above room temperatures. The lights of the coil-EEFL lamps are generated by the moving electrons in the superconductive vacuum between Ar atoms, giving rise to the astronomical high quantum efficiency of $10^{13}$ visible photons $\left(\mathrm{m}^{3} \cdot \mathrm{s}\right)^{-1}$. The numbers of the moving electrons in the FL lamps are $10^{15}$ electrons $\left(\mathrm{m}^{3} \cdot \mathrm{s}\right)^{-1}$. The illuminance $\left(300 \mathrm{~lm} \cdot \mathrm{m}^{-2}\right)$ of the coil-EEFL lamps are given by the $10^{25}$ visible photons $\left(\mathrm{m}^{3} \cdot \mathrm{s}\right)^{-1}$. The FL lamps are operated with the coexistence of the disparity of the external and internal electric circuits in the lighted FL lamps. The coil-EEFL lamps are operated with the DC electric circuit that the cathode and anode are formed with the volumes of the glow light on the polarized phosphor particles under the EE electrodes. The electric power consumption of 10 coil-EEFL lamps in the parallel connection is $\mathrm{W}_{\mathrm{DC}}=0$ with the operation life longer than $10^{6}$ hours. The developed coil-EEFL lamps will contribute to the Green Energy Project by UN.

\section{Acknowledgements}

The author wishes to express his great appreciation to Mr. Nobuyoshi Ohtani and Dr. Takao Toryu for their instruction and chance to early study on the characteristic properties of the phosphor powders from the basics with the hand-made instruments in the small laboratory modified from the green house in Chigasaki, Japan before 1953. They also instructed the author that the results of the study should contribute to human society rather than personal benefit. Since then, the author has continued his study on the material science by the hand-made instruments for the development of the new products on his life.

\section{References}

[1] Ozawa, L. (2015) Development of New Electron Sources for Coil-EEFL Tube. Science Research, 3, 220-229. https://doi.org/10.11648/j.sr.20150304.20

[2] Ozawa, L. (2015) Coil-EEFL Tubes as Unrivaled Light Source with Small $\mathrm{W}_{\text {coil }}$ over Solid Light Source. Science Research, 3, 230-239. https://doi.org/10.11648/j.sr.20150304.21

[3] Ozawa, L. (2015) Coil-EEFL Tube as Supreme Incandescent Light Source with Zero Electric Power Consumption, Astronomical Quantum Efficiency, and Long Life. Global Journal of Science Frontier Research: A Physics and Space Science, 15, 16-50.

[4] Ozawa, L. (1994) Application of Cathodoluminescence to Display Devices. Kodansha, Tokyo.

[5] Machelet, R.R. (1926) US Pat. 1612387.

[6] Mayer, F. (1928) US Pat. 2182732.

[7] Waymouth, J.F. (1971) Electron Discharge Lamp, MIT Press.

[8] Flower, R.H. and Nordheim, L.W. (1928) Proceedings of the Royal Society of London. Series A, 119, 173. https://doi.org/10.1098/rspa.1928.0091 
[9] (1973) Handbook of Electric Discharge Lamps. Japanese Institute of Electric Engineering.

[10] (2003) Handbook of Physics and Chemistry. CRC Press, Taylor \& Francis Group, Boca Raton, London, New York.

[11] William, Y. (2003) Phosphor Handbook. 2nd Edition, CRC Press, Taylor \& Francis Group, Boca Raton, London, New York.

[12] American Vacuum Society Classics (1993) (1) The Fundamental Data on Electrical Discharge Gases, (2) Field Emission and Field Ionization, (3) Vacuum Technology and Space Simulation, (4) The Physical Basics of Ultrahigh Vacuum, (5) Handbook of Electron Tube and Vacuum Techniques, (6) Vacuum Sealing Techniques, and (7) Ionized Gases. American Institute of Physics.

[13] Ozawa, L. and Tian, Y. (2013) A Breakthrough in the Study on FL Tubes. Journal of Chinese Illumination Society, 8, 86-94.

[14] Ozawa, L. and Tian, Y. (2012) A New 4G Electron Source for Fluorescent Lamp Tubes. Journal Chinese Illumination Engineering Society, 7, 58-66.

[15] Ozawa, L. (2016) Unrivalled Incandescent Lamp for Green Energy Project. World Journal of Applied Physics, 1, 1-15. http://www.Sciencepublicationgroup.com/j/fap

[16] Ozawa, L. (2017) Ideal Distribution of Polycrystalline Phosphor Particles for the Application to Phosphor Screen in CRT. International Journal of Material Science and Applications, 6, 6-17. https://doi.org/10.11648/j.ijmsa.20170601.12

[17] Ozawa, L. (1990) Cathodoluminescence, Theory and Applications. Kodansha, Tokyo.

Ozawa, L. (2009) Cathodoluminescence and Photoluminescence, Theories and Practical Applications. CRC Press, Taylor \& Francis Group, Boca Raton, London, New York.

[18] Ozawa, L. (2015) Illuminance of FL Tubes Controlled by Depths of Gap between Positive Column and Phosphor Screen. Science Research, 3, 93-104. https://doi.org/10.11648/j.sr.20150303.18

[19] Ozawa, L. (2015) Electric Charges on Phosphor Particles Determine Features of the Lighted FL Tubes. International Journal of Engineering Science \& Research Technology, 4, 91107. http://www.ijesrt.com

[20] Ozawa, L. (2015) Special Arrangement of Phosphor Particles in Screen for Optimization of Illuminance $\left(\mathrm{lm}, \mathrm{m}^{-2}\right)$ of FL Tubes. Science Research, 3, 261-272. https://doi.org/10.11648/j.sr.20150306.11 


\section{Biography}

The author started production of the FL lamp on 1948. On 1950, he moved to the phosphor production at a very small factory in Japan. Then he moved to USA on 1968. He studied all his life on the luminescent materials and application of it to the lighting devices, like as the most advanced monochrome and color CRTs, and FL lamps. He has studied the properties of the luminescent materials by the hand-made equipments. He had increased 10 times of the luminance $\left(\mathrm{cd} \cdot \mathrm{m}^{-2}\right)$ of color CRT on 1968 to 1971 at Zenith, USA. He also developed the miniature CRT in the highest image quality in Japan on 1993 for the application to the virtual reality device. The highest image quality of the color CRT had developed in Korea on 1998. He obtained the certificates of the graduation of high school, the degree of bachelor in science, and then consultant in the applied science from Japanese Government. He worked as professor of Tianjin Technological Institute in China. He has classified as the extra-ordinary ability person from USA Government. He wrote 4 books of the luminescence, 5 review articles, and more than 90 articles in the professional Journals. 